\title{
Activating Developmental Reserve Capacity Via Cognitive Training or Non-invasive Brain Stimulation: Potentials for Promoting Fronto-Parietal and Hippocampal-Striatal Network Functions in Old Age
}

\author{
Susanne Passow ${ }^{*}$, Franka Thurm and Shu-Chen Li \\ Chair of Lifespan Developmental Neuroscience, Department of Psychology, TU Dresden, Dresden, Germany
}

\section{OPEN ACCESS}

Edited by:

Pamela M. Greenwood, George Mason University, USA

Reviewed by:

Min-Fang Kuo,

Leibniz Research Centre for Working Environment and Human Factors,

Germany

Elzbieta Szelag,

Nencki Institute of Experimental

Biology, Poland

Yee Lee Shing

Max Planck Institute for Human Development (MPG), Germany

*Correspondence:

Susanne Passow susanne.passow@tu-dresden.de

Received: 23 September 2016 Accepted: 08 February 2017 Published: 23 February 2017

Citation:

Passow S, Thurm F and Li S-C (2017) Activating Developmental Reserve Capacity Via Cognitive Training or Non-invasive Brain Stimulation: Potentials for Promoting Fronto-Parietal and Hippocampal-Striatal Network Functions in Old Age.

Front. Aging Neurosci. 9:33. doi: 10.3389/fnagi.2017.00033
Existing neurocomputational and empirical data link deficient neuromodulation of the fronto-parietal and hippocampal-striatal circuitries with aging-related increase in processing noise and declines in various cognitive functions. Specifically, the theory of aging neuronal gain control postulates that aging-related suboptimal neuromodulation may attenuate neuronal gain control, which yields computational consequences on reducing the signal-to-noise-ratio of synaptic signal transmission and hampering information processing within and between cortical networks. Intervention methods such as cognitive training and non-invasive brain stimulation, e.g., transcranial direct current stimulation (tDCS), have been considered as means to buffer cognitive functions or delay cognitive decline in old age. However, to date the reported effect sizes of immediate training gains and maintenance effects of a variety of cognitive trainings are small to moderate at best; moreover, training-related transfer effects to non-trained but closely related (i.e., near-transfer) or other (i.e., far-transfer) cognitive functions are inconsistent or lacking. Similarly, although applying different tDCS protocols to reduce aging-related cognitive impairments by inducing temporary changes in cortical excitability seem somewhat promising, evidence of effects on short- and long-term plasticity is still equivocal. In this article, we will review and critically discuss existing findings of cognitive training- and stimulation-related behavioral and neural plasticity effects in the context of cognitive aging, focusing specifically on working memory and episodic memory functions, which are subserved by the fronto-parietal and hippocampal-striatal networks, respectively. Furthermore, in line with the theory of aging neuronal gain control we will highlight that developing age-specific brain stimulation protocols and the concurrent applications of tDCS during cognitive training may potentially facilitate short- and long-term cognitive and brain plasticity in old age.

Keywords: aging, neuronal gain control, dopamine, fronto-parietal network, hippocampal-striatal network, cognitive training, transcranial electrical stimulation 


\section{INTRODUCTION}

Normal aging is accompanied by alterations in multiple cognitive functions with negative consequences on various daily activities. Facing the historically unprecedented global challenge of demographic change, with larger populations of individuals older than 65 years than the populations of youths younger than 20 years (Harper, 2014), a crucial agenda of gerontopsychology and geronto-neuroscience is to develop interventions that could activate the reduced but still available cognitive and brain resources in old age to buffer and delay cognitive declines. Indeed, early investigations of cognitive plasticity in the elderly provided evidence for the concept of developmental reserve capacity, which illustrates the malleability of older adults' cognitive performance been enhanced by environmental supports (Baltes et al., 1986; Baltes, 1987). Results from neurocomputational studies and empirical research provide compelling support for a close link between neuromodulation and cognitive functions. For instance, neurocomputational studies have contributed to the current understandings of cholinergic (Sarter et al., 2014), serotoninergic (Dayan and Huys, 2009) and dopaminergic (Servan-Schreiber et al., 1990; Li et al., 2001; Montague et al., 2004) systems in regulating neuronal information transmissions and their computational consequences on cognition and behavior. Of particular relevance in the context of aging, the efficacy of the cholinergic (Ellis et al., 2009; Mitsis et al., 2009; Richter et al., 2014), serotoninergic (Wong et al., 1984; Yamamoto et al., 2002; Nord et al., 2014), and dopaminergic (see Bäckman et al., 2010; Li and Rieckmann, 2014 for reviews) modulations decline substantially during the course of normal aging. The computational theory of aging neuronal gain control (Li et al., 2001) explicates a sequence of computational mechanisms that associate agingrelated deficient dopaminergic neuromodulation with a variety of cognitive aging deficits. Specifically, in the simulated "old networks" deficient dopamine (DA) modulation is modeled by reducing the gain control (modeled with a lower slope) of the information transfer function that relates pre-synaptic signal input and post-synaptic response activities (Figure 1A). Consequently, the signal-to-noise ratio (SNR) of information processing is decreased in the simulated "old" network with a lower gain control, resulting in increased random processing fluctuations (Figure 1B), and consequently attenuated rate (drift rate, $v$ ) of evidence accumulation (Figure 1C). Generalizing from these mechanisms, other simulation studies showed that the thus simulated "old network" exhibited less distinctive representations of activation patterns and less selective recruitment of specific processing modules that accounted for aging-related declines in working memory (Li and Sikström, 2002). Furthermore, associative memory deficit (Li et al., 2005) as well as a range of other cognitive impairments commonly observed in old age could also be accounted for by the aging neuronal gain control theory (see Li and Rieckmann, 2014, for a recent review).

Notwithstanding declines in neurocognitive resources, considerable "latent reserve capacity" at the cognitive and brain levels are still preserved in old age (cf. Baltes et al., 1986), which, given appropriate environmental supports or interventions, could potentially be activated to promote successful aging (Rowe and Kahn, 1987). In particular, the concept of "developmental reserve capacity" was introduced to denote the extent that an individual's maximum cognitive performance level could be enhanced through structured environmental supports i.e., interventions (Baltes, 1987). In this context, "baseline reserve capacity" reflects the amount of available neurocognitive resources at a given moment for certain cognitive operations, whereas "developmental reserve capacity" more specifically highlights the extent of older adults' potential to benefit from interventions in raising the levels of their cognitive functions. Couched in the terms of a more recent conceptual framework of adult cognitive plasticity (Lövdén et al., 2010), activating "developmental reserve capacity" in this context denotes the potential of raising the level of organismic supplies of functional resources in older adults through interventions.

In this article, we review existing findings of cognitive training and non-invasive brain stimulation interventions i.e., transcranial direct current stimulation (tDCS) and discuss their promises and constraints in activating the reduced but still available neurocognitive resources to buffer or ameliorate older adults' cognitive functions. Furthermore, we also consider and review first promising evidence from concurrent applications of tDCS during cognitive training as means to further promote short- and long-term training effects on cognitive and brain plasticity in old age. We will discuss the potential underlying mechanisms of these positive effects within the theoretical framework of neuronal gain control, namely how cognitive training and/or brain stimulation intervention may enhance dopaminergic neurotransmission and consequently modulate the SNR of information processing with performance enhancing effects in older adults. We will focus specifically on working memory and episodic memory functions, which are supported by the fronto-parietal and hippocampal-striatal circuitries, respectively.

\section{AGING-RELATED DECLINES IN FRONTO-PARIETAL AND HIPPOCAMPAL-STRIATAL MEMORY FUNCTIONS}

\section{Aging-Related Declines in Working Memory}

Cognitive control functions are described as the ability to flexibly adapt behavior by facilitating relevant over competing irrelevant information processing in order to achieve specific goals. Hence, the ability to manipulate and maintain goalrelevant information over a short period of time i.e., working memory, is essential (e.g., Engle, 2002; Cowan et al., 2005; Miller and Wallis, 2009; Fukuda et al., 2010). For instance, the content and information provided by task instructions must be actively represented and kept in mind to bias attentional allocation and response selection toward task-related goals, particularly when an inappropriate response is dominant and needs to be suppressed. Neurocognitive models of working memory suggest a dynamic interplay between prefrontal and parietal brain 
A DA modulation of neuronal gain control

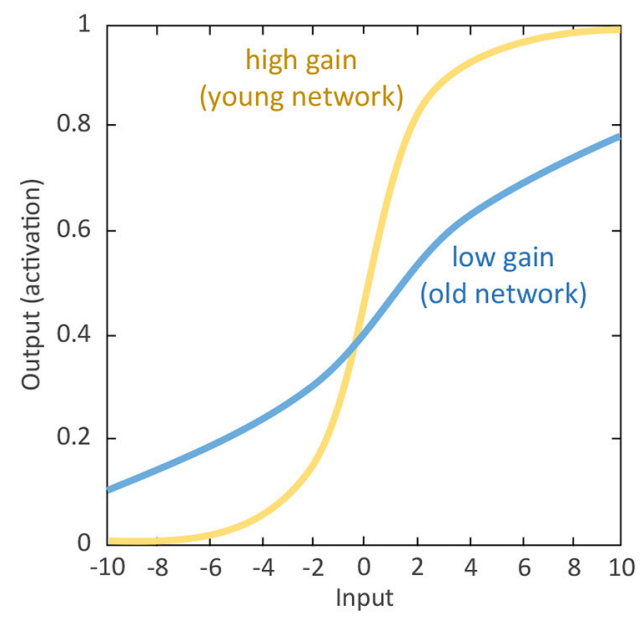

B Inefficient neuronal gain control of SNR

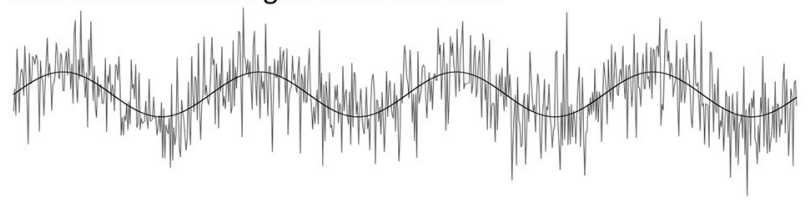

C Functional consequences of neuronal gain control efficacy
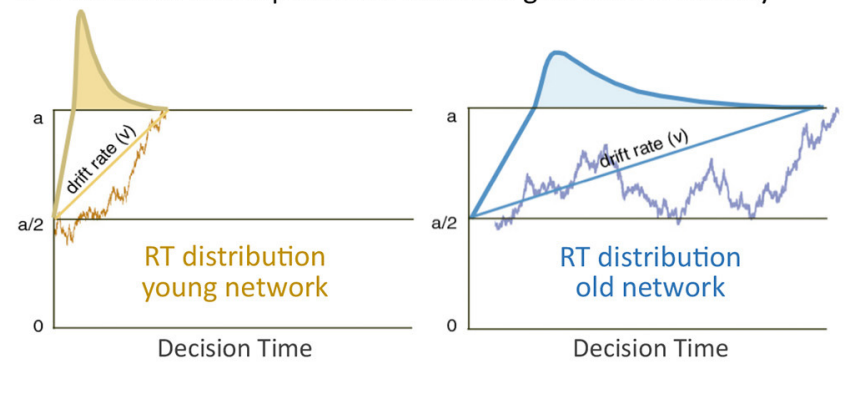

FIGURE 1 | Simulating computational effects of aging neuronal gain control: (A) Aging-related deficiency of dopamine (DA) modulation attenuates the gain parameter of the sigmoidal transfer function relating pre-synaptic input and post-synaptic output and thus reduces the slope of the neuronal response function. (B) Attenuated gain control increases random processing fluctuations, which functionally reduce the signal-to-noise ratio (SNR) of information processing. (C) For instance, in a simple decision process between criterion a or 0 , increased SNR of information processing limits the rate (drift rate, v) of evidence accumulation for either decision and precision of information processing with broader reaction time (RT) distribution, indicated by the curves, in the old compared to the young network. Further negative impacts on a wide range of cognitive functions have been discussed (Li et al., 2001; see Li and Rieckmann, 2014 for commonly observed neurocognitive aging deficits accounted for by the simulated effects of aging neuronal gain control).

areas (D’Esposito, 2007; Linden, 2007; Darki and Klingberg, 2015). Posterior brain regions seem to play important roles in forming and maintaining representations, whereas prefrontal regions contribute to the selection of relevant information and the stabilization of representations during maintenance (Postle, 2006). Moreover, the fronto-striatal circuitry also implicates working memory (e.g., Cools et al., 2008; McNab and Klingberg, 2008; Darki and Klingberg, 2015). Critically, frontal and basal ganglia activity precede the filtering of irrelevant information during working memory encoding and predict storage-related parietal activity as well as inter-individual differences in working memory capacity (McNab and Klingberg, 2008).

On the neurochemical level, it has been shown that different neurotransmitters, such as serotonin (Luciana et al., 1998; CanoColino et al., 2014), norepinephrine (Zhang et al., 2013), and acetylcholine (Hasselmo and Stern, 2006) are involved in working memory processes (see Ellis and Nathan, 2001 for review). We focus on the role of DA here as its roles for working memory processes is best established (e.g., Sawaguchi and GoldmanRakic, 1991; Goldman-Rakic, 1996; Arnsten, 1998; Braver and Cohen, 2000; Durstewitz et al., 2000a,b; Frank et al., 2001; Cools et al., 2008; D’Ardenne et al., 2012). Evidence from animal and human studies show that maintenance processes are supported by prefrontal DA signaling (e.g., Williams and GoldmanRakic, 1995; Goldman-Rakic, 1996; Abi-Dargham et al., 2002). Accordingly, the dual-state theory of prefrontal DA function proposes the existence of two discrete, dynamic, and functionally different states. A D1-receptor dominated state that favors robust maintenance of information in working memory despite distractions and a D2-receptor dominated state contributing to the flexible integration of new information (Durstewitz and Seamans, 2008). Besides the role of prefrontal DA signaling in working memory processes, neurocomputational models (Braver and Cohen, 2000; Frank et al., 2001) and empirical work (D’Ardenne et al., 2012) suggest that DA signaling in the basal ganglia acts as a gating mechanism, which regulates the encoding of new information in the prefrontal cortex (PFC) and consequently the updating of context information in working memory. Selective lesions of prefrontal DA neurons in animals were associated with increased striatal DA release (Roberts et al., 1994), while enhancing DA activity in the PFC inhibited striatal DA release (Kolachana et al., 1995; Karreman and Moghaddam, 1996). Furthermore, an overexpression of D2 receptors in the striatum led to alterations in prefrontal D1 receptor activity and consequently functional impairments in working memory and behavioral flexibility tasks (Kellendonk et al., 2006). Taken together, being closely intertwined via the cortico-striato-cortical pathway the interactions between prefrontal and striatal DA systems are crucial for working memory processes and adaptive, goal-directed behavior.

There is a wealth of evidence that normal aging is accompanied by significant declines in working memory (e.g., Bopp and Verhaeghen, 2005; Borella et al., 2008; Li et al., 2008; see Lever et al., 2006; Sander et al., 2012 for reviews). At the brain functional level, aging-related changes in working memory are associated with altered task-related activations in prefrontal and posterior brain regions in older compared to younger adults (e.g., Grady et al., 1998; Cabeza et al., 2004; see Rajah and D'Esposito, 2005 for review; Rypma and D'Esposito, 2000; Schneider-Garces et al., 2010). Similarly, compared to younger 
adults, older adults did not show significant striatal activation during a working memory task before training intervention (Dahlin et al., 2008a). At the neurochemical level, there is ample evidence that the density of pre-synaptic (DA transporter) and post-synaptic (D1 and D2 receptors) DA markers in striatal and extra-striatal regions decline markedly from early to late adulthood (see Bäckman et al., 2010 for review). Lesion and pharmacological animal studies provide direct evidence that DA depletion (Brozoski et al., 1979; Collins et al., 1998) but also excessive DA receptor stimulation (Murphy et al., 1996; Zahrt et al., 1997) in the PFC had negative consequences for working memory functions. For instance, depletion of DA in the dorsolateral prefrontal cortex (DLPFC) in rhesus monkeys resulted in impaired working memory performance, which could be pharmacologically reversed by the DA precursor levodopa and the DA agonist apomorphine (Brozoski et al., 1979). In humans, reduced frontal and striatal DA markers were associated with an under-recruitment of the fronto-parietal network during working memory (Landau et al., 2009; Bäckman et al., 2011a) as well as reduced fronto-striatal (Klostermann et al., 2012) and fronto-parietal (Rieckmann et al., 2011) functional connectivity. Interindividual differences in caudate D1 receptor density were related to interindividual differences in functional connectivity of the right DLPFC to the right parietal cortex and of the medial PFC to the right intraparietal sulcus and postcentral gyrus during working memory performance (Rieckmann et al., 2011). In a similar vein, Klostermann et al. (2012) could show that suboptimal levels of DA synthesis capacity in the caudate were correlated with reduced functional connectivity between the right inferior frontal gyrus and the caudate, which in turn was associated with decreased working memory performance. Thus, aging-related differences in functional activations and connectivity in the cortico-striato-cortical pathway seem to be linked to suboptimal DA signaling and may underlie agingrelated changes in working memory performance.

\section{Aging-Related Declines in Episodic Memory and Spatial Learning}

The memory of experienced events i.e., episodic memory, encompasses multiple facets of information. For instance, the memory about a conversation includes the content of the conversation, the persons involved as well as the time and spatial location in which the conversation took place. Associative memory mechanisms are required to bind the different aspects of an experience into an integrated episode in long-term memory. The fronto-hippocampal circuitry implicates the strategic organization and elaboration of memory materials as well as the binding of different aspects of memory features during encoding, memory consolidation, and memory retrieval (Simons and Spiers, 2003), for instance pattern association which describes the function to link certain input and certain memory patterns to enable memory retrieval also with varying input patterns. Relative to semantic memory (i.e., memory for specific facts or knowledge), older adults are particularly impaired in episodic strategic organization and elaboration that are subserved by the frontal executive control processes as well as associative mechanisms that implicate the hippocampal regions (Chalfonte and Johnson, 1996; Old and Naveh-Benjamin, 2008; Shing et al., 2008). For instance, older adults' episodic memory deficit was particularly apparent in conditions requiring the memorization of associations between memory items (Naveh-Benjamin, 2000) relative to memory of single items. The aging neuronal gain control theory accounted for older adults' associative binding deficit through the less distinctive representations of the associations between items, which was the computational consequence of attenuated gain control in the memory network ( $\mathrm{Li}$ et al., 2005). Moreover, ample evidence from functional magnetic resonance imaging (fMRI) and positron emissions tomography (PET) studies relates deficits in episodic memory encoding and retrieval in old age with alterations in functional episodic memory networks, especially with patterns of functional under-recruitment and non-selective additional bilateral recruitment of prefrontal regions, which is not observed in younger adults (see Reuter-Lorenz, 2002; Nyberg et al., 2012 for review). For instance, during episodic memory encoding older adults showed additional activation in right frontal regions while at the same time task-relevant left frontal regions were under-recruited, probably due to insufficient (i.e., non-selective) allocation of brain resources (e.g., Logan et al., 2002; Leshikar et al., 2010). Similarly, during episodic memory retrieval, older adults showed reduced selectivity of prefrontal activation during context (Cabeza et al., 2000) and recognition memory tasks (Madden et al., 1999) and reduced specificity of prefrontal and hippocampal activations during retrieval of item vs. relational memory information (Giovanello and Schacter, 2012). Simulation results from the aging neuronal gain control theory indicate that such aging-related increases of non-specific recruitments of presumably distinct processing pathways may, in part, be related to deficient DA modulation of the underlying task relevant networks (Li and Sikström, 2002).

One other specific aspect of episodic memory i.e., the spatial configuration of a memory episode, relies particularly on the hippocampal-striatal circuitry (see Moser et al., 2008 for review). Animal research showed that, whereas complex representations of spatial layouts and locations relative to environmental geometric features (e.g., spatial boundaries and shapes of the environment) are supported by the hippocampus (e.g., O’Keefe and Dostrovsky, 1971; O’Keefe and Burgess, 1996; Hartley et al., 2000), the computationally less demanding cuebased spatial learning (e.g., using fixed cue-location associations) is mainly subserved by the dorsal striatum (e.g., Packard et al., 1989; Packard and McGaugh, 1992; McDonald and White, 1994; Miyoshi et al., 2012). Applying desktop virtual reality-based fMRI spatial navigation tasks in humans, a similar dissociation was shown in healthy young adults with stronger hippocampal involvement during spatial exploration of new routes and during learning and remembering of object locations relative to a visible boundary; whereas, stronger striatal activation was shown during route following and during learning and remembering of object locations relative to an intra-environmental cue (e.g., Hartley et al., 2003; Iaria et al., 2003; Wolbers and Büchel, 2005; Doeller et al., 2008). 
Younger adults further showed a prioritization of relying on hippocampal-dependent spatial over striatal-dependent cuebased navigation strategies (e.g., Bohbot et al., 2012; Wiener et al., 2013). Other aspects of spatial navigation such as path integration that strongly rely on self-motion without the need of visual input also involve hippocampal-based spatial processing. Path integration, however, implicates additional human motion complex activity together with working memoryrelated location updating and monitoring processes of the medial PFC (e.g., Wolbers et al., 2007; De Nigris et al., 2013) and performance differences in path integration across human adulthood are, so far, not entirely understood (e.g., Harris et al., 2012, but Skolimowska et al., 2011). The complexity of the brain network underlying spatial navigation notwithstanding, we will in the following primarily focus on spatial memory subserved by the hippocampal-striatal circuitry.

Of specific interest, the relative prioritization of hippocampaland striatal-dependent processes of spatial learning is influenced by aging. With increasing age, spatial learning, and memory decline, with an overall bias toward relying on cue-based strategies and recruitments of striatal regions (e.g., Moffat and Resnick, 2002; Driscoll et al., 2005; Bohbot et al., 2012; Etchamendy et al., 2012; Harris et al., 2012; Rodgers et al., 2012; Konishi and Bohbot, 2013; Wiener et al., 2013; Schuck et al., 2015). Specifically, whereas younger adults' behavioral data and hippocampal activity was consistent with a computational model predicting object locations relative to the geometry of the virtual environment's boundary, older adults' navigation behavior was best predicted by a model interfering object locations relative to an intra-maze location cue and was associated with larger caudate than hippocampal activation. Behaviorally, aging-related deficits in spatial learning were more prominent in hippocampaldependent boundary learning than in striatal-dependent cuebased learning (Schuck et al., 2015). Previous research indicated that aging-related structural and neurobiological alterations in the hippocampus (see Rosenzweig and Barnes, 2003 for review; Wilson et al., 2006) as well as neuromodulatory changes in the midbrain DA system (see Bäckman et al., 2010; Li and Rieckmann, 2014 for reviews) might contribute to deficits in spatial learning and memory in old age. During normal aging, hippocampal volume progressively declines by $1-2 \%$ per year (Raz et al., 2005), which presumably affects spatial memory performance in old age (Erickson et al., 2011). Based on evidence from animal studies, the aging hippocampus, especially the perforant path receiving input from the entorhinal cortex, is further characterized by a multitude of subtle alterations in synaptic plasticity, including loss and shrinkage of synapses (Geinisman et al., 1992; Smith et al., 2000; Nicholson et al., 2004), reduced excitability leading to increasing stimulation thresholds (Barnes et al., 1994, 2000) and faster decay of long-term potentiation (Landfield et al., 1978; Barnes and McNaughton, 1985). Atrophy of the perforant path was also observed in healthy older compared to younger adults using diffusion tensor imaging (Kalus et al., 2006) and was even more pronounced in postmortem brain tissue of older adults with mild cognitive impairment (MCI) despite otherwise comparable volumes in the unimpaired and MCI groups (Scheff et al., 2006). Moreover, the extent of synaptic loss in the perforant path was negatively correlated with pre-mortem memory status. Taken together, aging-related changes in structure and function of the hippocampus may at least in part underlie older adults' increased reliance on striatal-dependent cue-based navigation strategies.

Evidence from animal research indicates that midbrain DA modulation of the hippocampus plays an important role in stabilizing transient memory traces and maintaining encoded memory associations in long-term memory (Bethus et al., 2010; see Lisman and Grace, 2005 for review; Rossato et al., 2009). In the context of spatial learning, Kentros et al. (2004) showed that DA D1/D5 agonist enhances the stability of hippocampal place fields in rats. In humans, a recent pharmacological imaging study showed that a DA agonist and DA precursor levodopa enhanced episodic memory and brain activation in older adults (Chowdhury et al., 2012). Relatedly, recent behavioral genetic evidence showed that genetic predispositions of DA transporter (DAT1) and receptor $(D R D 2)$ genes are associated with individual differences in serial memory ( $\mathrm{Li}$ et al., 2013) and long-term episodic memory forgetting, particularly in older adults (Papenberg et al., 2013). In terms of spatial learning, a recent study with Parkinson's (PD) patients showed that, after the patients had some prior experiences with a given spatial environment, the prioritization of hippocampal-dependent boundary learning was increased relative to striatal-dependent cue-based learning when they were on dopaminergic medication (Thurm et al., 2016).

Taken together, in the two sections above we have reviewed findings indicating that normal aging is associated with prominent declines in working memory and episodic memory, with negative consequences for older adults' daily activities. Structural and functional changes as well as aging-related suboptimal dopaminergic neuromodulation in the frontostriatal-parietal and fronto-hippocampal-striatal brain network, respectively, may contribute to these aging-related working memory and episodic memory impairments. According to the framework of the aging neuronal gain control theory ( $\mathrm{Li}$ et al., 2001), reduced working memory and episodic memory capacity may stem from suboptimal DA modulation of the relevant networks, which may impair the SNR of information transfer within and between the respective brain circuitries, thus causing reduced specificity of information processing and less distinctive brain activation patterns. Facing increasing population aging, developing interventions that could activate the developmental reserve capacity in older adults and augment the aging brain's attenuated neuronal gain control to maintain or promote working memory and episodic memory functions (see Figure 2 for a schematic diagram) is of high societal relevance. In the following sections, evidence for why cognitive training and non-invasive brain stimulation can be seen as potential candidate interventions for promoting the aging brain's neuronal gain control will be reviewed, alongside with critical discussions about the short- and long-term effects of these interventions. 


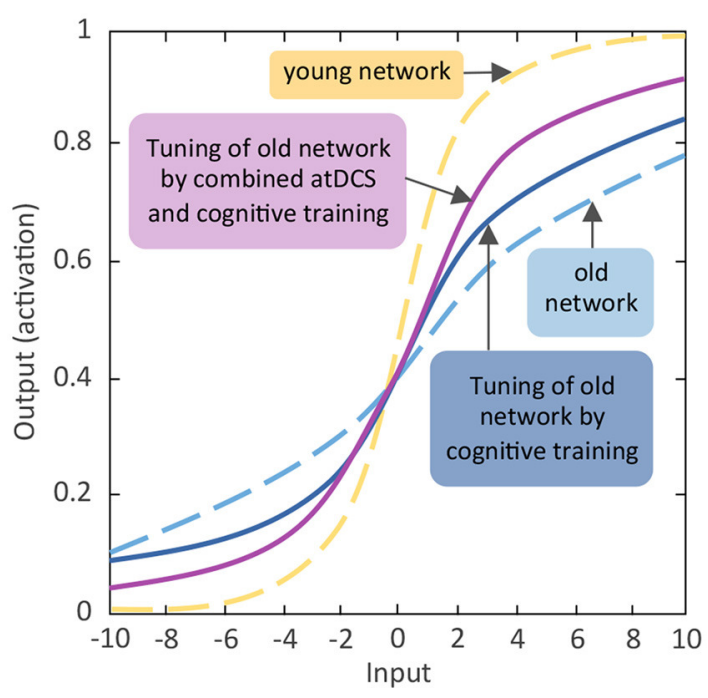

FIGURE 2 | Schematic diagram of expected effects of activating aging neuronal gain control through cognitive training and non-invasive brain stimulation. Comparable to Figure 1A the $y$-axis indicates the activation value of units of the artificial neural network. The activation value as bounded by the sigmoidal activation function is between 0 and 1 . The $x$-axis denotes incoming excitatory or inhibitory inputs, which ranged from -10 to +10 . The $\mathrm{s}$-shaped logistic activation function transforms the net inputs into the strength of an output signal. The responsivity of a unit to inhibitory or excitatory inputs is modulated by the slope of the function, which is regulated by the gain parameter (see Li et al., 2001). Reducing the slope flattens the activation function and the unit becomes less responsive, whereas steepening the slope of the function enhances the responsivity.

\section{INTERVENTION METHODS ENHANCING NEURONAL GAIN CONTROL}

\section{Behavioral Training Interventions Enhancing Neuronal Gain Control}

Ameliorating older adults' cognitive decline through behavioral interventions has received a lot of attention during the last couple of years. Thus, a plethora of heterogeneous intervention methods has been developed and evaluated. For instance, cognitive, physical or combined cognitive and physical interventions (see Bamidis et al., 2014 for review) as well as action video game training (see Bavelier et al., 2012 for review) have been shown to induce behavioral and/ or brain plasticity effects. In the following we will primarily focus on cognitive training interventions in the working memory and episodic memory domain and refer readers interested in other interventions methods to the cited reviews.

Cognitive training promotes structural changes in the brain's gray and white matter. According to the animal literature, candidate cellular mechanisms underlying gray matter plasticity encompass axon sprouting, dendritic branching and synaptogenesis, neurogenesis and glial changes (see Zatorre et al., 2012 for review). Beyond these structural changes, of specific relevance in the context of this review is the evidence for training-induced changes in neurotransmitter systems. For instance, animal studies showed that motor training in rats seems to increase the expression of muscarinic acetylcholine
(Ibarra et al., 1995) and DA (MacRae et al., 1987; Soiza-Reilly et al., 2004) receptors in the striatum. Spatial working memory training in monkeys has been shown to induce a reduction in the variability of firing rates across trials and a decline in cross-trial correlations of neuronal discharges, suggesting that training could lower random processing fluctuation which functionally increases the SNR of information processing and the precision of stimulus representations in PFC neurons (Qi and Constantinidis, 2012a,b). Of note, human studies using PET imaging in younger adults provide evidence for traininginduced changes in striatal (Bäckman et al., 2011b) and cortical dopaminergic neuromodulation that were associated with larger working memory training gains (McNab et al., 2009). Taken these findings together, training interventions seem to be promising candidates to enhance neuronal gain control in older adults and thus promote cognitive and brain plasticity, with potential transfer effects to other functions than the trained domains. In the following, we will review in more details adult age differences in working memory and episodic memory plasticity. Other than focusing on training gains of the trained tasks, improvements in non-trained tasks closely related to working memory or episodic memory (so-called near-transfer effects), performance gains in other functional domains (so-called far-transfer effects), and stability of training- and transfer-effects (maintenance effect) will be highlighted.

\section{Age Differences in Working Memory Training-Induced Behavioral and Brain Plasticity}

Lifespan age differences in cognitive plasticity following training seems to vary across cognitive domains, with comparable effect sizes of immediate working memory training gains across younger and older adults (Schmiedek et al., 2010; Karbach and Verhaeghen, 2014). In contrast, near- and far-transfer effects were shown to be present in younger adults ( e.g., Jaeggi et al., 2008; Chein and Morrison, 2010) but reduced or absent in older adults (e.g., Buschkuehl et al., 2008; Dahlin et al., 2008b; Li et al., 2008; Schmiedek et al., 2010; Richmond et al., 2011; Brehmer et al., 2012). With regard to maintenance effects in older adults there is evidence that training and transfer-effects of working memory training remain stable over a period of months (Dahlin et al., 2008b; Li et al., 2008; Borella et al., 2010; Richmond et al., 2011; Zinke et al., 2014).

Working memory training studies in humans have revealed quantitative changes in functional activation (see Constantinidis and Klingberg, 2016 for review; Olesen et al., 2004; Dahlin et al., 2008a; Jolles et al., 2013; Kühn et al., 2013; Thompson et al., 2016) and DA signaling (McNab et al., 2009; Bäckman et al., 2011b) of the fronto-striatal-parietal network (see Figure 3 for an overview diagram). For instance, compared to pretraining fronto-parietal functional connectivity increased in younger adults (Jolles et al., 2013; Thompson et al., 2016). Furthermore, changes in striatal brain activity have also been observed and associated with working memory training-induced improvements (Dahlin et al., 2008a; Kühn et al., 2013). Of note, using PET imaging in humans, $\mathrm{McNab}$ and colleagues provide evidence for a training-induced enhancement in cortical 


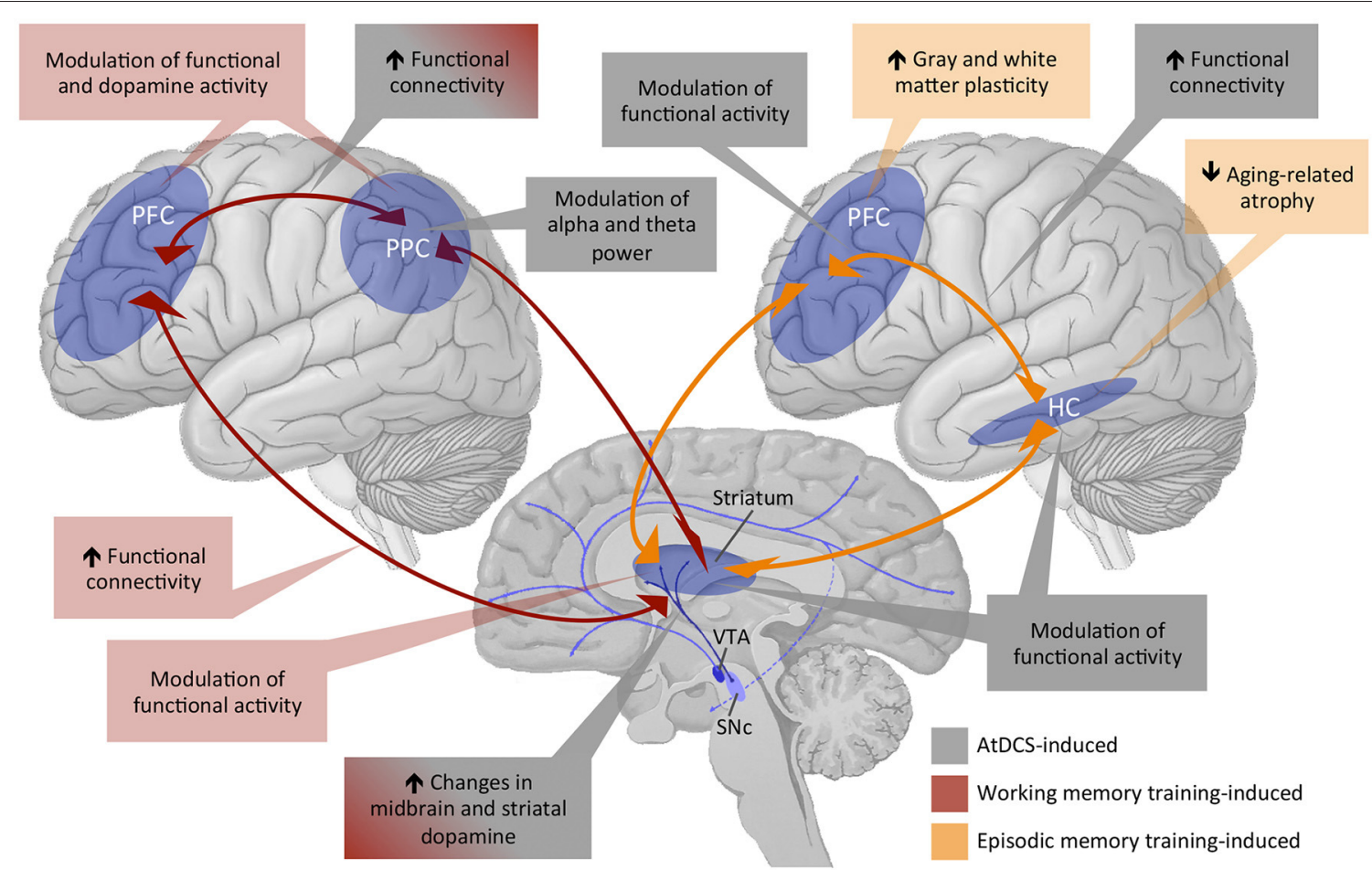

FIGURE 3 | Overview of existing evidence of training and tDCS effects on working memory and episodic memory functions subserved by the fronto-striatal-parietal and fronto-hippocampal-striatal circuitries. PFC, prefrontal cortex; PPC, posterior parietal cortex; HC, hippocampus; VTA, ventral tegmental area; SNc, subthalamic nucleus; AtDCS, anodal transcranial direct current stimulation.

DA neuromodulation that is reflected by reduced D1-receptor binding potential, which could reflect enhanced DA release after training in task-relevant brain areas. Individuals who showed greater training-induced changes in D1 receptor binding potential also showed greater training-related improvements in working memory performance (McNab et al., 2009). A further PET imaging study could show that working memory training results in enhanced striatal DA release in younger adults (Bäckman et al., 2011b).

So far, studies investigating the neural correlates of working memory training in older adults are rather scarce. There is evidence for training-induced decreases in cortical brain activations (frontal, parietal, temporal, occipital), pointing to an increase in neural efficiency, and training-induced increases in subcortical (thalamus and caudate) brain activations. Critically, the degree of the striatal changes was associated with training gains (Brehmer et al., 2011). Regarding transfer effects of working memory training, Dahlin and colleagues indicated that younger adults' transfer effects were based on traininginduced increases in striatal activity in the trained and transfer task whereas this was not the case in older adults (Dahlin et al., 2008a). Thus, based on these results and given the working memory training-induced effects on striatal DA release (Bäckman et al., 2011b), aging-related reduction in transfer effects in older adults may be driven by their deficient striatal DA functioning.

\section{Age Differences in Episodic Memory Training-Induced Behavioral and Brain Plasticity}

Episodic memory plasticity has been shown to be more limited in old age compared to young adulthood or childhood (see Brehmer et al., 2007; Shing et al., 2010 for review; Shing et al., 2008). These age differences in training-induced plasticity are more pronounced for episodic compared to working memory (see Lindenberger, 2014 for review; Schmiedek et al., 2010). Notwithstanding the more limited episodic memory plasticity in old age, cognitive interventions might be able to reduce aging-related performance disadvantages by providing sufficient environmental support (cf. Lindenberger, 2014). For instance, aging-related under-recruitment in prefrontal regions can be reversed when encoding strategies are externally provided rather than self-initiated by the participants (Logan et al., 2002).

Early episodic memory training interventions mainly focused on instructing mnemonic (e.g., method of loci) and other memory strategies in order to facilitate task-specific encoding or retrieval in younger and older adults (see Brehmer et al., 2014 for review). For instance, Brehmer and colleagues compared the effects of a multisession mnemonic training in a lifespan sample, from childhood to old age. As a function of mnemonic instruction and adaptive training, all age groups showed improvements in the trained memory task but with older adults clearly showing the smallest training gains (Brehmer et al., 2007). Other studies showed equivocal or less promising results of 
various memory trainings (e.g., Jennings et al., 2005; Craik et al., 2007; Lustig and Flegal, 2008). In the very old (i.e., older adults aged 75-100 years or older), memory plasticity seems to be further reduced resulting in observable but very small negligible gains from instruction and adaptive practice compared to old adults below the age of 75 years (Singer et al., 2003). Training gains in very old age might be increased when memory training is combined with other training modules (Oswald et al., 2006) or intervention techniques.

In the COGITO study (Schmiedek et al., 2010), 100 days of memory training with verbal, numerical, and spatial material was associated with reliable near-transfer effects in both younger and older adults. However, the effect sizes for performed episodic memory tasks and latent cognitive variables were rather small in older adults (latent effect size of .09 compared to .52 in younger adults). Similarly, the ACTIVE study investigated potential fartransfer effects to functions of everyday life in older adults by comparing a verbal memory, a speed of processing, and a reasoning training with a passive control group. Cognitive training involved 10 sessions of $60-75 \mathrm{~min}$ over 5-6 weeks, followed by four additional training sessions two and 5 years after the initial training intervention was completed. The memory training group showed significant practice gains in the trained cognitive domain, which were stable up to 5 years after the intervention, but no further gains following additional training and no far-transfer effects of the memory training or the additional memory training on measures of everyday life functioning could be observed (Ball et al., 2002; Willis et al., 2006). Overall, the literature indicates that older adults can benefit from episodic memory training but direct training gains, so far, are much smaller compared to younger age groups and other cognitive domains. Furthermore, evident (far)-transfer effects are limited at best or lacking (cf. Noack et al., 2009, 2014).

The small behavioral effects with regard to transfer and generalizability notwithstanding, episodic memory traininginduced alterations in brain structure and function have been reported (see Figure 3 for an overview diagram). For instance, at the structural level, memory training was associated with increases in cortical thickness and gray matter volume in younger, middle-aged and older adults (Engvig et al., 2010, 2012, 2014). Training-induced improvements in memory performance were further positively correlated with the extent of cortical thickness increase in the lateral orbitofrontal cortex and the right fusiform gyrus (Engvig et al., 2010) and with the extent of volume increase in the left hippocampus (Engvig et al., 2014). A further study investigated effects of a spatial memory training i.e., episodic memory training with spatial context, on cognitive and structural brain plasticity in younger and older adults. Four months of spatial memory training in a virtual zoo not only facilitated task performance but also counteracted aging-related hippocampus shrinkage up to 4 months after training in both age groups (Lövdén et al., 2012). However, training-related cortical thickening in the left paracentral lobule and precuneus were only evident in younger but not in older participants (Wenger et al., 2012), indicating that aging-related differences in traininginduced structural plasticity are region-specific. Additionally, hippocampal volume prior to cognitive interventions might be one predictor of memory training outcomes in old age (Engvig et al., 2012). At the functional level, effects of episodic memory training have, so far, mainly been observed in the fronto-parietal network (Nyberg et al., 2003). After being instructed to use the method of loci as a mnemonic strategy, increased brain activities in frontal as well as occipito-parietal regions were observed in younger adults. In contrast, accompanying their reduced episodic memory plasticity as indicated by the reduced training gain, older adults did not show training-related increase in frontal activity, and only those older adults who benefited from the memory training showed increased occipito-parietal activity. Moreover, animal literature indicates that DA plays a crucial role for longterm maintenance of episodic memory training-induced effects (Rossato et al., 2009; Bethus et al., 2010), although direct evidence of enhanced DA modulation after episodic memory training is still lacking. Brain-derived neurotrophic factor (BDNF) might be one further factor modulating DA effects on episodic memory consolidation following training in rodents (Rossato et al., 2009) and spatial memory training-induced effects on cognitive and brain plasticity in adult humans (Lövdén et al., 2011).

In summary, both working memory and episodic memory training research reveal that cognitive plasticity following interventions is more limited in older adults and this is particularly so in the domain of episodic memory. So far, evidence for the transfer of training-effects to related or other cognitive processes (i.e., near- and far-transfer effects) in older adults is rare. This may reflect that solely relying on cognitive training interventions could be limited in their effects in promoting behavioral and brain plasticity in older adults (see Figure 2 for a schematic diagram). Thus, other interventions or the combination of training with other intervention methods need to be explored. Since the last 15 years transcranial electrical stimulation methods (tES) are receiving increasing attention in the field of behavioral and brain plasticity. In the following, we will briefly highlight in what ways tES, particularly anodal transcranial direct current stimulation (atDCS), may be suitable for the enhancement of neuronal gain control and thus cognitive performance in older adults. Afterwards, we will review current existing findings about the behavioral and brain plasticity effects of atDCS applications in the field of working memory and episodic memory.

\section{Transcranial Direct Current Stimulation (tDCS) as a Means for Enhancing Neuronal Gain Control}

Transcranial direct current stimulation (tDCS) in which a constant, low intensity current $(1-2 \mathrm{~mA})$ is passed through two electrodes is one commonly applied stimulation mode in the field of tES techniques. Besides tDCS, tES techniques also encompass transcranial alternating current stimulation (tACS) in which a sinusoidal current is applied to modulate brain oscillatory activity and transcranial random noise stimulation (tRNS) in which current intensity and frequency vary in a random manner (see Antal and Herrmann, 2016 for review). During the last couple of years the number of published articles on tES-induced effects on cognition has increased tremendously. The endeavor of 
reviewing findings of all three tES methods on working memory and episodic memory functions would be beyond the scope of this article. As tDCS is the most systematically studied tES method, we limited our review on tDCS studies only.

During tDCS subthreshold changes of neuronal resting membrane potentials are induced, which alter cortical excitability and activity, dependent on the direction of the current flow. Studies of stimulating the human motor cortex have shown that anodal tDCS (atDCS) facilitates, while cathodal tDCS (ctDCS) reduces excitability. Stimulations lasting for a few seconds seems to induce solely changes in membrane potentials, while longerlasting stimulation for a few minutes induce changes in cortical excitability, which remain stable for about $1 \mathrm{~h}$ or longer (see Kuo and Nitsche, 2015 for review; Nitsche and Paulus, 2000, 2001). Studies applying atDCS have shown beneficial effects on cognitive functions in young (e.g., see Brunoni and Vanderhasselt for review; Parasuraman et al., 2014; Scheldrup et al., 2014), and old age (e.g., Berryhill and Jones, 2012; see Hsu et al., 2015 for review; Flöel et al., 2012), presumably by enhancing excitability (Nitsche and Paulus, 2000, 2001), facilitating synaptic (Stagg et al., 2009; Stagg and Nitsche, 2011), neural (Islam et al., 1995) and cognitive plasticity (see Filmer et al., 2014 for review; Liebetanz et al., 2002; Flöel and Cohen, 2010), and by changing brain network connectivity (e.g., Meinzer et al., 2012; Sehm et al., 2012).

Non-invasive brain stimulation techniques seem to have a modulatory effect on dopaminergic neurotransmission (Strafella et al., 2001; Keck et al., 2002; Cho and Strafella, 2009; Tanaka et al., 2013). For instance, repetitive transcranial magnetic stimulation (rTMS) over prefrontal brain regions has been shown to induce increased extracellular DA levels in striatal (Strafella et al., 2001; Keck et al., 2002) and extra-striatal brain regions i.e., anterior cingulate and orbitofrontal cortex (Cho and Strafella, 2009). With regard to tDCS an animal study provides direct evidence for a modulatory effect of tDCS on dopaminergic neurotransmission. More specifically, extracellular DA levels in the striatum of rats increased for more than 400 min following the application of $10 \mathrm{~min}$ cortical ctDCS but not atDCS (Tanaka et al., 2013). Combined tDCS and drugintervention studies further support a link between DA and tDCS-induced excitability and neuroplastic after-effects (Nitsche et al., 2006; Kuo et al., 2008; Monte-Silva et al., 2010; Fresnoza et al., 2014a,b). For instance, levodopa significantly prolongs the after-effects of tDCS applied over the motor cortex (Kuo et al., 2008), but in a non-linear, dose-dependent manner (Monte-Silva et al., 2010). More specifically, low and high dosage of levodopa abolished excitatory as well as inhibitory modulatory effects of $\mathrm{tDCS}$, whereas a medium dosage turned excitatory into inhibitory plasticity and prolonged inhibitory plasticity effects. Taken together, although the exact underlying mechanisms are yet not completely understood, tDCS-induced plasticity effects seem to be partly driven by changes in the dopaminergic system. Evidence of neurocomputational, receptor imaging, and behavioral genetic studies suggests that deficient dopaminergic neurotransmission contribute to aging-related declines in working memory and episodic memory (see Li and Rieckmann for review) and older adults' reduced plasticity
(Kishore et al., 2014). Consequently, tDCS interventions may be a promising tool for enhancing behavioral and neural plasticity via modulating dopaminergic signaling. Within the theoretical framework of neuronal gain control tDCS-induced improvements in dopaminergic neurotransmission are likely to enhance the gain control of the information transfer function and consequently improve the SNR of information processing in older adults resulting in higher representational distinctiveness and more selective recruitment of relevant processing modules. In terms of functional consequences this more efficient processing is likely to lead to behavioral and neural benefits in working memory and episodic memory functions. In the following two sections, we will review findings on the effects of tDCS on behavioral and brain plasticity in the domains of working memory and episodic memory (for an overview of tDCS-study characteristics see Table 1).

\section{Effects of tDCS on Working Memory Plasticity}

As aforementioned, working memory processes rely on a broad network encompassing frontal, parietal and striatal brain regions. During the last couple of years a plethora of studies assessing tDCS effects on working memory performance in humans targeting frontal and parietal stimulation sites have been published, for instance, $10 \mathrm{~min}$ of ctDCS with a current intensity of $1.5 \mathrm{~mA}$ over the right posterior parietal cortex (PPC; P4 electrode site of the International 10-20 system) impaired working memory performance dependent on the specific working memory process that was probed. Recognition performance was impaired, whereas verbal recall of the encoded objects remained unchanged. Interestingly, atDCS did not show any effect (Berryhill et al., 2010). Inconsistent with these findings, Tseng et al. (2012) could show that $15 \mathrm{~min}$ of $1.5 \mathrm{~mA}$ atDCS but not ctDCS over the right PPC had a performance enhancing effect in a visual change-detection paradigm. There is also evidence that effects of tDCS over the right PPC were only apparent for a more challenging task and that younger adults with high working memory capacity benefited from either atDCS or ctDCS application, whereas those with low working memory capacity did not (Jones and Berryhill, 2012). In contrast, applying atDCS over the right PPC revealed that participants with low compared to those with high working memory capacity performed better in a difficult change detection task during atDCS (Tseng et al., 2012). Thus, tDCS over the posterior parietal cortex seems to modulate working memory performance, but the type and the consequences of stimulation are inconsistent. The resulting heterogeneity across studies may be due to differences in task paradigms, corresponding task difficulty and interindividual differences in baseline working memory capacity. Studies investigating the effects of atDCS over the left PFC on working memory performance (e.g., Ohn et al., 2008; Andrews et al., 2011; Zaehle et al., 2011) reported more consistent performance enhancing effects. In order to reduce heterogeneity across studies a recent meta-analysis included only non-invasive brain stimulation (NIBS) studies assessing the effects of atDCS and rTMS effects over the right, left or bilateral DLPFC on performance in n-back tasks. Critically 
TABLE 1 | Overview of characteristics of working memory and episodic memory tDCS studies.

\begin{tabular}{|c|c|c|c|c|c|c|c|c|c|}
\hline \multirow[t]{2}{*}{ Authors } & \multirow[t]{2}{*}{ Design } & \multirow{2}{*}{$\begin{array}{l}\text { Conditions } \\
\text { (excluding } \\
\text { sham) }\end{array}$} & \multicolumn{4}{|c|}{ tDCS set-up } & \multicolumn{3}{|c|}{ Task sample } \\
\hline & & & Anode-Cathode & $\begin{array}{l}\text { Density } \\
\left(\mathrm{mA} / \mathrm{cm}^{2}\right)\end{array}$ & $\begin{array}{l}\text { Duration } \\
\text { (min) }\end{array}$ & & $N$ & Age & Female \% \\
\hline \multicolumn{10}{|l|}{ WORKING MEMORY } \\
\hline \multirow[t]{2}{*}{ Berryhill et al., 2010} & Cross-over & 1 & left cheek-P4 & 0.043 & 10 & WM & 11 & 25.0 & 45 \\
\hline & & 2 & P4-left cheek & 0.043 & 10 & WM & 11 & 25.0 & 45 \\
\hline Tseng et al., 2012 & Cross-over & 1 & P4-left cheek & 0.094 & 15 & WM & 20 & 22.0 & 65 \\
\hline \multirow[t]{2}{*}{ Jones and Berryhill, 2012} & Cross-over & 1 & left cheek-P4 & 0.043 & 10 & WM & 20 & 23.25 & 60 \\
\hline & & 2 & P4-left cheek & 0.043 & 10 & WM & 20 & 23.25 & 60 \\
\hline \multirow[t]{2}{*}{ Zaehle et al., 2011} & Cross-over & 1 & left mastoid-F3 & 0.029 & 15 & WM & 16 & $23.0-27.0$ & 62.5 \\
\hline & & 2 & F3-left mastoid & 0.029 & 15 & WM & 16 & 23.0-27.0 & 62.5 \\
\hline \multirow[t]{2}{*}{ Berryhill and Jones, 2012} & Cross-over & 1 & F3-right cheek & 0.043 & 10 & WM & 25 & 63.7 & 57 \\
\hline & & 2 & F4-left cheek & 0.043 & 10 & WM & 25 & 63.7 & 57 \\
\hline \multirow[t]{2}{*}{ Nilsson et al., 2015} & Cross-over & 1 & F3-right SO & 0.029 & 25 & WM & 30 & $69.0 \pm 7.0$ & 46.7 \\
\hline & & 2 & F3-right SO & 0.057 & 25 & WM & 30 & $69.0 \pm 7.0$ & 46.7 \\
\hline \multicolumn{10}{|l|}{ EPISODIC MEMORY } \\
\hline \multirow[t]{2}{*}{ Manenti et al., 2013} & $\begin{array}{l}\text { Cross-over/ } \\
\text { between }\end{array}$ & 1 & left/right DLPFC/PARC-cSO & 0.043 & & LTM & 32 & $23.7 \pm 3.2$ & 71.9 \\
\hline & & 2 & left/right DLPFC/PARC-cSO & 0.043 & & LTM & 32 & $67.9 \pm 4.7$ & 53.1 \\
\hline \multirow[t]{2}{*}{ Sandrini et al., 2014} & Between & 1 (reminder) & F3-right SO & 0.043 & 15 & LTM & 12 & $67.5 \pm 2.7$ & 66.7 \\
\hline & & 2 (no reminder) & F3-right SO & 0.043 & 15 & LTM & 12 & $67.6 \pm 4.3$ & 66.7 \\
\hline Sandrini et al., 2016 & Between & 1 & F3-right SO & 0.043 & 15 & LTM & 14 & $68.6 \pm 4.2$ & 64.3 \\
\hline \multirow[t]{2}{*}{ Smirni et al., 2015} & $\begin{array}{l}\text { Cross-over/ } \\
\text { between }\end{array}$ & 1 & shoulder-F3/F4 & 0.029 & 20 & LTM & 20 & $23.6 \pm 2.3$ & 88.9 \\
\hline & & 2 & F3/F4-shoulder & 0.029 & 20 & LTM & 16 & $24.7 \pm 2.2$ & 88.9 \\
\hline \multirow[t]{2}{*}{ Zwissler et al., 2014} & Between & 1 & F3-right shoulder & 0.029 & 15 & LTM & 24 & $24.8 \pm 2.9$ & 62.5 \\
\hline & & 2 & right shoulder-F3 & 0.029 & 15 & LTM & 24 & $24.8 \pm 2.9$ & 62.5 \\
\hline $\begin{array}{l}\text { Jones et al., } 2014 \\
\text { (tDCS-encoding) }\end{array}$ & Cross-over & 1 & P3-right cheek & 0.043 & 15 & LTM & 20 & $23.4 \pm 3.3$ & 75 \\
\hline $\begin{array}{l}\text { Jones et al., } 2014 \\
\text { (tDCS-maintenance) }\end{array}$ & Cross-over & 1 & P3-right cheek & 0.043 & 15 & LTM & 20 & $22.2 \pm 2.5$ & 70 \\
\hline \multirow[t]{2}{*}{ Pisoni et al., 2015} & Between & 1 & P3-P4 & 0.043 & 15 & LTM & 15 & $23.5 \pm 2.6$ & \\
\hline & & 2 & T3-T4 & 0.043 & 15 & LTM & 15 & $23.1 \pm 3.5$ & \\
\hline \multirow[t]{2}{*}{ Boggio et al., 2009} & Cross-over & 1 & F3-right SO & 0.057 & 30 & LTM & 10 & $79.1 \pm 8.8$ & 60 \\
\hline & & 2 & T7-right SO & 0.057 & 30 & LTM & 10 & $79.1 \pm 8.8$ & 60 \\
\hline \multirow[t]{2}{*}{ Ferrucci et al., 2008} & Cross-over & 1 & P3/T5-P6/T4-shoulder & 0.057 & 15 & LTM & 10 & $75.2 \pm 7.3$ & 70 \\
\hline & & 2 & shoulder-P3/T5-P6/T4 & 0.057 & 15 & LTM & 10 & $75.2 \pm 7.3$ & 70 \\
\hline \multirow[t]{2}{*}{ Brunyé et al., 2014} & $\begin{array}{l}\text { Cross-over/ } \\
\text { between }\end{array}$ & 1 & T8-CP6, FC6, FT10, TP10 & HDtDCS & up to 20 & SM & 16 & 20.1 & 0 \\
\hline & & 2 & T7-CPS, FC5, FT9, TP9 & HDtDCS & up to 20 & SM & 16 & 20.1 & \\
\hline \multirow[t]{2}{*}{ Hampstead et al., 2014} & Between & 1 & $\mathrm{Pz}-\mathrm{AF} 4$ & 0.057 & 20 & SM & 8 & $24.6 \pm 2.4$ & 50 \\
\hline & & 2 & AF4-Pz & 0.057 & 20 & SM & & $24.4 \pm 5.1$ & 37.5 \\
\hline \multirow[t]{2}{*}{ Krishnamurthy et al., 2015} & Between & 1 & Pz-AF4 & 0.057 & 20 & rs-fMRI & & $19-27$ & 33.3 \\
\hline & & 2 & AF4-Pz & 0.057 & 20 & rs-fMRI & & $19-27$ & 33.3 \\
\hline Flöel et al., 2012 & Cross-over & 1 & P6-left SO & 0.029 & 2 & SM & 20 & $62.1 \pm 9.2$ & 50 \\
\hline
\end{tabular}

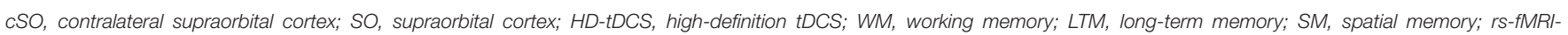
resting-state functional magnetic resonance imaging; $N$, number of participants; PARC, parietal cortex.

for the current review, atDCS was shown to improve n-back performance, which was reflected by shorter reaction times, when compared to sham tDCS. This pattern of results was present across different stimulus intensities, stimulus durations, and in healthy and clinical samples (see Brunoni and Vanderhasselt, 2014 for review). Unfortunately, effect sizes in dependence of stimulation site i.e., right, left, or bilateral DLPFC, were not further discussed. 
Studies investigating the underlying neuronal mechanisms of tDCS-induced effects on working memory performance are scarce (for an overview see Figure 3). Zaehle et al. (2011) studied working memory performance after a single application of $15 \mathrm{~min} 1 \mathrm{~mA}$ atDCS or ctDCS over the left DLPFC and the corresponding changes in oscillatory activity by using electroencephalography (EEG). The results revealed that tDCS altered working memory performance and changed the underlying neural oscillations at posterior electrode sites in a polarity-specific way (Zaehle et al., 2011). Specifically, atDCS amplified, whereas ctDCS attenuated oscillatory power in the theta and alpha bands, which are both critical for working memory processes. Local increases in alpha amplitude are related with preventing uptake of irrelevant information during working memory retention, whereas theta oscillations are thought to play an important role in the integration and organization of the different cognitive processes involved in working memory (see Sauseng et al., 2010 for review). Investigating the effects of atDCS over the left DLPFC on brain network connectivity using resting-state $\mathrm{fMRI}$ indicated a significant increase in functional connectivity in the default-mode and left and right frontoparietal resting-state network (Keeser et al., 2011). The relevance of fronto-parietal functional connectivty for working memory is well established (e.g., Hampson et al., 2010; Rieckmann et al., 2011), but a direct link between tDCS-induced alterations in resting-state functional connectitvity and changes in working memory performance remains to be determined.

Evidence for enhancing effects of atDCS on cognitive functions in older adults is much more limited than in younger adults but slowly accumulating. Recent meta-analyses lend support for enhancing effects of NIBS methods on cognitive performance in older adults (Hsu et al., 2015; Summers et al., 2016). Hsu et al. (2015), for instance, considered studies examining tDCS and also TMS effects on performance across a broad variety of tasks targeting different cognitive processes (e.g., working memory, episodic memory, inhibition, error awareness). The meta-analysis revealed an overall moderate effect size (0.42). However, a systematic review and meta-analysis comparable to Brunoni and Vanderhasselt (2014) including only studies applying stimulation over the same brain area, the same working memory paradigm, and analyzing the same outcome measures in older adults is unfortunately still missing. Overall there are mixed results for atDCS-effects on working memory performance in older adults. For instance, Berryhill and Jones (2012) conducted a sham-controlled experiment with atDCS over the DLPFC before a visuo-spatial and verbal working memory task. The anode was placed either over the F3 or F4 electrode site of the 10-20 International system and $1.5 \mathrm{~mA}$ direct current was applied for $10 \mathrm{~min}$. The results indicated that atDCS improved working memory performance independently of stimulation site. Critically, only older adults with high education levels showed the stimulation effect, which may reflect that highly educated older adults employ a different working memory strategy that can be boosted by atDCS compared to older adults with lower levels of education (Berryhill and Jones, 2012). More recently, Nilsson et al. (2015) systematically investigated the influence of atDCS over the left DLPFC on performance in an n-back task in older adults. The authors compared different current intensities ( 1 vs. $2 \mathrm{~mA}$ ) and investigated the temporal development of the atDCS effect i.e., n-back performance was assessed before, three times during, 5 and $30 \mathrm{~min}$ after the 25 min-stimulation period. The results revealed no significant effects of atDCS. Compared to sham stimulation atDCS did not modulate working memory performance at any point during or after stimulation (Nilsson et al., 2015). These results should be interpreted with caution, as possible practice effects due to multiple testing in sham and atDCS stimulation conditions may have masked the stimulation effects. However, the lack of a robust effect after a singular application of tDCS is consistent with a meta-analysis, indicating that multi-session stimulations are more effective than single-session stimulations in older adults (Hsu et al., 2015).

\section{Effects of tDCS on Episodic Memory Plasticity}

Most studies investigating potential facilitating effects of atDCS on episodic memory functions focused on verbal and visual memory, which are memory functions subserved by a broader fronto-hippocampal-parietal circuitry. As direct stimulation of critical subcortical structures such as the hippocampus or striatum is not applicable in healthy human subjects, network activations via the stimulation of cortical areas as the frontal and parietal cortex are commonly applied. There is evidence indicating that, relative to sham or control site conditions, atDCS stimulation of the left DLPFC with a current of 1-2 $\mathrm{mA}$ for up to $20 \mathrm{~min}$ during or immediately after encoding of the stimulus material improved immediate recognition and retrieval or reduced long-term forgetting of verbal and visual episodic memories in younger (e.g., Javadi and Walsh, 2012; Manenti et al., 2013; Gray et al., 2015) and older adults (e.g., Manenti et al., 2013; Sandrini et al., 2014, 2016). Stimulation effects were independent of stimulation hemisphere in young adulthood but memory improvements in older adults were only observed following left hemisphere stimulation (Manenti et al., 2013). Nevertheless, beneficial stimulation effects have also been observed $48 \mathrm{~h}$ later (Sandrini et al., 2014, 2016) or up to 1 month after applying atDCS (Sandrini et al., 2014) in older adults. However, there are also other studies that failed to replicate these results in younger adults (Smirni et al., 2015) or even reported an increase of false alarm rates in episodic memory (Zwissler et al., 2014).

Fewer studies involving younger adults investigated potential effects of atDCS over the temporal or parietal cortices. For instance, Jones and colleagues showed facilitations in verbal longterm memory in younger adults when atDCS was administered during encoding but not during maintenance over the left PPC with a current of $1.5 \mathrm{~mA}$ for $15 \mathrm{~min}$ (Jones et al., 2014). Bilateral atDCS (i.e., the anode over the left and the cathode over the right temporal cortex or the PPC) during the recognition phase of a word list learning task showed differential effects in younger adults: recognition performance of old (hit) but not new items (correct rejection) was improved in the temporal cortex stimulation group whereas recognition performance of new but not old items was improved in the PPC stimulation group (Pisoni et al., 2015). Such findings indicate that potential effects of facilitation vs. inhibition of new afferent information 
depend on the stimulation site and, hence, on the underlying brain circuitry of the respective cognitive domain. Evidence from healthy aging studies is, so far, missing, but improvements in recognition memory up to 4 weeks after stimulation (over the left DLPFC or bilateral over temporoparietal areas with $1.5-2 \mathrm{~mA}$ for 15-30 $\mathrm{min}$ ) had been observed in Alzheimer's disease patients (Ferrucci et al., 2008; Boggio et al., 2009).

Thus, far, there are even fewer studies, which investigated effects of tDCS on spatial learning and memory. Nevertheless, the available results offer some optimism regarding tDCSinduced spatial memory plasticity in the adult lifespan. In younger adults, applying atDCS at $2 \mathrm{~mA}$ for $20 \mathrm{~min}$ over the right centrotemporal cortex during spatial navigation in a virtual environment facilitated later performance in a sketch map drawing test that required the participants to re-draw the layout of the virtual environment from memory. Interindividual differences in the sense of direction predicted atDCS-induced spatial navigation benefits, with low-performing individuals benefitting more (Brunyé et al., 2014).

Regarding the underlying neural correlates, animal literature, so far, provides only tentative evidence that BDNF and neurogenesis in the dentate gyrus might play a role in atDCS-induced improvements in episodic and spatial memory performance (see Bennabi et al., 2014 for review). Recent studies combining tDCS with fMRI investigated the effects of tDCS on activation and functional connectivity within the frontohippocampal-striatal network in humans (Hampstead et al., 2014; Krishnamurthy et al., 2015; see Figure 3 for an overview diagram). Network-modulatory effects of tDCS were investigated by applying $20 \mathrm{~min}$ of $2 \mathrm{~mA}$ tDCS offline before the participants performed a spatial navigation task assessing hippocampal- vs. striatal-based spatial memory in the MR scanner. The anode and cathode were placed over midline parietal and frontal regions, respectively. The parietal-anode/frontal-cathode montage had no effect on hippocampal activity in both hippocampal- and striataldependent spatial navigation conditions but was associated with increased right caudate activation during sequential stimulusresponse-based spatial navigation and greater connectivity between the left prefrontal and the parietal cortex. In contrast, the frontal-anode/parietal-cathode montage was associated with increased right hippocampal and bilateral activity in prefrontal regions during hippocampus-dependent navigation and with greater connectivity between prefrontal regions and the right hippocampus (Hampstead et al., 2014). The parietalanode/frontal-cathode montage was further associated with increased fMRI resting-state functional connectivity between the superior parietal lobule and other brain regions of the spatial learning and memory network $10 \mathrm{~min}$ after the stimulation (Krishnamurthy et al., 2015). To our knowledge, only one study has, so far, investigated effects of atDCS on spatial memory in healthy older adults (Flöel et al., 2012). In a 2sessions within-subject cross-over design, atDCS with a current of $1 \mathrm{~mA}$ for $20 \mathrm{~min}$ over the right temporoparietal cortex was applied during the learning phase of an object-location learning paradigm. Despite lacking tDCS-induced effects during learning, healthy older adults showed tDCS-induced benefits of memory recall 1 week after stimulation, indicating that tDCS can have medium- to long-term effects on spatial memory even in old age.

Taken together, only a small number of studies have investigated the effects of atDCS on episodic and spatial memory in older adults and existing findings indicate further needs of systematic investigations. Of note, in the domain of working memory the results are rather mixed. Two possible factors may explain the, for now, inconsistent results. Given that interindividual variability in widespread changes in brain physiology and brain plasticity increase with old age, optimal tDCS parameters (i.e., current intensity, stimulation duration, and frequency, electrode montage) for applications in older adults can be expected to differ from those for younger adults (Zimerman and Hummel, 2010; Fertonani et al., 2014). Thus, developing age-appropriate stimulation protocols require more systematic investigations. Furthermore, across various cognitive functions multi-session tDCS applications seem to be more efficient compared to single-session application in older adults (Hsu et al., 2015). Thus, tDCS applied in combination with cognitive training over multiple sessions may provide the added neural boost for enhancing and prolonging transfer effects that are known to be reduced or lacking in older adults (see Figure 2 for a schematic diagram).

\section{COMBINING COGNITIVE TRAINING AND tDCS}

Very recently, a few studies have started to explore the effects of combining motor learning (Reis et al., 2009) or cognitive training with atDCS interventions in younger (Meinzer et al., 2014; Richmond et al., 2014; Au et al., 2016; Looi et al., 2016; Mancuso et al., 2016) and older adults (Jones et al., 2015b; Stephens and Berryhill, 2016). In younger adults, first evidence for atDCS-enhancing effects on training gains have been shown across various cognitive functions, e.g., arithmetic operations (Looi et al., 2016), language (Meinzer et al., 2014), and working memory (Richmond et al., 2014; Au et al., 2016). For episodic memory though, there is yet no study investigating synergistic effects of atDCS and episodic memory training neither in healthy young nor older populations. There is, to the best of our knowledge, only one study that applied $2 \mathrm{~mA}$ atDCS for $25 \mathrm{~min}$ over the left DLPFC during 10 sessions of memory training in Alzheimer's disease patients without being able to show ameliorating effects of atDCS on the training-related memory improvements (Cotelli et al., 2014).

With respect to working memory, Richmond et al. (2014) let their participants take part in an adaptive training over 10 sessions concurrent with either $15 \mathrm{~min}$ of $1.5 \mathrm{~mA}$ atDCS or sham stimulation over the left DLPFC. The results showed that compared to sham stimulation atDCS enhanced learning and near-transfer to other non-trained working memory tasks. Fartransfer or maintenance effects were not investigated. Enhanced training performance due to additional atDCS could also be reported by $\mathrm{Au}$ et al. (2016). In seven sessions participants 
received $25 \mathrm{~min}$ of $2 \mathrm{~mA}$ atDCS over the right or left DLPFC concurrent with a visual-spatial working memory training. Near-transfer to non-trained visual or spatial working memory tasks could also be observed but only in the right DLPFC stimulation group which is in line with the right-hemispheric dominance of the DLPFC for spatial working memory functions (Wager and Smith, 2003). Critically, the authors also assessed maintenance effects and could show that the atDCS- enhanced training effects remained stable up to 8 months after training completion (Au et al., 2016). Thus, there is promising evidence for prefrontal atDCS-enhancing effects on immediate training gains and near-transfer effects. The effects on far-transfer effects still need to be explored. Taken together, the currently existing empirical findings in younger adults lend support to the idea that concurrent atDCS-training applications might bolster older adults' limited working memory training and transfer gains.

There is already some preliminary but promising evidence suggesting that older adults can benefit from combined atDCS and training interventions. For instance, older participants who received $30 \mathrm{~min}$ of $2 \mathrm{~mA}$ atDCS over the DLPFC during 10 sessions of computer-based cognitive training showed greater improvements in verbal working memory compared to a sham stimulation group. This effect maintained up to 28 days (Park et al., 2014). Near- and far-transfer effects were not assessed. Jones et al. (2015b) could provide evidence for maintenance effects of atDCS on training-related improvements and transfer effects in older adults. In their study older adults received sham or atDCS over the right DLPFC, parietal, or alternating prefrontal/parietal cortices (stimulation site was varied across training sessions). The participants were randomly assigned to one of the four groups and were matched according to age, education and cognitive status. In 10 sessions, after $10 \mathrm{~min}$ of $1.5 \mathrm{~mA}$ tDCS participants performed a working memory task. All groups benefited from working memory training and showed significant improvements in the trained and near-transfer tasks. Critically, after 1 month of no contact, only the participants in the atDCS group maintained the significant improvement for the trained and near-transfer tasks. Interestingly, the magnitude of this improvement did not vary as a function of stimulation site condition indicating that all stimulation sites equally well targeted the fronto-parietal network, which could also be confirmed by current modeling (Jones et al., 2015b). In a more recent study of the same group, standard far-transfer effects (i.e., processing speed, cognitive flexibility, arithmetic) and ecologically valid far-transfer effects were assessed to investigate translation to other cognitive abilities and daily activities as e.g., scheduling appointments, driving, safety awareness, and route planning. In this study older adults took part in a 5day working memory training combined with 15 min of either sham, 1, or $2 \mathrm{~mA}$ atDCS over the right DLPFC. Comparable to their first study, the authors replicated the general improvement in the trained task across all groups. Critically, $2 \mathrm{~mA}$ atDCS induced significantly greater far-transfer gains after 1 month of no contact (Stephens and Berryhill, 2016). Taken together, working memory training when combined with atDCS seems to offer promise in enhancing and maintaining older adults's working memory training as well as near- and far-transfer gains. Whether the effect sizes of atDCS-enhancing training gains in older adults are comparable to those of younger adults needs to be determined.

\section{LIMITATIONS AND OUTLOOK}

Notwithstanding the promising effects of combined atDCS and cognitive training interventions, there are several open questions and limitations that should be addressed in future studies. As there was no comparison group in all the combined atDCS and cognitive training studies that underwent only tDCS, no firm conclusions about the synergistic effects of brain stimulation and cognitive training intervention can yet be drawn. Thus, future work should include a tDCS-only control group to clarify whether tDCS, cognitive training and the combination of tDCS and cognitive training contribute differently to shortand long-term benefits. The response to tDCS has been shown to be state-dependent and critically vary as a function of interindividual differences in educational level (Berryhill and Jones, 2012) or baseline task performance (Jones and Berryhill, 2012; Tseng et al., 2012). It is likely that tDCS interacts with individual endogenous activity levels within the region of targeted neurons, rather than exerting a homogeneous effect across individuals (Learmonth et al., 2015). Further, the results of a previous study could show that tDCS effects were boosted after supplying a task strategy or financial motivation (Jones et al., 2015a). Thus, considerable attention should be paid to the thorough assessment of baseline task ability and the influences of motivational factors when designing future tDCS and combined tDCS and training interventions. Given the existence of an inverted-U relationship between DA level and cognition ( $\mathrm{Li}$ and Sikström, 2002; Cools and D’Esposito, 2011) and nonlinear, dose-dependent effects of levodopa on tDCS-induced plasticity (Monte-Silva et al., 2010), atDCS could also shift performance beyond the optimal range. Thus, interindividual differences in baseline DA-level should be kept in mind when interpreting interindividual differences in tDCS-induced effects. Furthermore, so far, we can only infer that the effects of combined tDCS and training interventions on working memory may be mediated through the strengthening of functional connectivity in the fronto-striatal-parietal as well as dopaminergic modulation of this circuitry (Jones et al., 2015b). Future fMRI and PET studies should, therefore, investigate the underlying neuronal mechanisms of combined tDCS and training effects in order to explore whether these effects go beyond the known traininginduced changes in brain activation and functional connectivity in the fronto-striatal-parietal network (e.g., Dahlin et al., 2008a; Jolles et al., 2013; Kühn et al., 2013; Thompson et al., 2016) as well as cortical and striatal DA signaling ( $\mathrm{McNab}$ et al., 2009; Bäckman et al., 2011b). Given that older adults' reduced cognitive plasticity following cognitive training interventions is particularly limited in the domain of episodic memory, future studies should investigate whether similarly promising results can be shown for episodic memory and maybe other cognitive domains. Furthermore, as older adults are particularly limited in 
transfer effects of cognitive training interventions, future work should by default include both, near- and far-transfer tasks and invest more effort in developing protocols that enable the investigation of transfer particularly to daily activities. Related to this, future work should also focus on the home-based applicability of combined tDCS and training interventions to pave ways for more ecologically valid interventions that may promote the maintenance of autonomy and quality of life in old age.

\section{AUTHOR CONTRIBUTIONS}

SP, FT, and SL did substantial contributions to the conception and design of the review article. SP, FT, and SL drafted the work and revised it critically for important intellectual content. SP, FT, and SL did the final approval of the version, to be published. Finally

\section{REFERENCES}

Abi-Dargham, A., Mawlawi, O., Lombardo, I., Gil, R., Martinez, D., Huang, Y. Y., et al. (2002). Prefrontal dopamine D-1 receptors and working memory in schizophrenia. J. Neurosci. 22, 3708-3719. doi: 10.1038/385634a0

Andrews, S. C., Hoy, K. E., Enticott, P. G., Daskalakis, Z. J., and Fitzgerald, P. B. (2011). Improving working memory: the effect of combining cognitive activity and anodal transcranial direct current stimulation to the left dorsolateral prefrontal cortex. Brain Stimul. 4, 84-89. doi: 10.1016/j.brs.2010. 06.004

Antal, A., and Herrmann, C. S. (2016). Transcranial alternating current and random noise stimulation: possible mechanisms. Neural Plast. 2016:3616807. doi: 10.1155/2016/3616807

Arnsten, A. F. (1998). Catecholamine modulation of prefrontal cortical cognitive function. Trends Cogn. Sci. 2, 436-447. doi: 10.1016/s1364-6613(98)01240-6

Au, J., Katz, B., Buschkuehl, M., Bunarjo, K., Senger, T., Zabel, C., et al. (2016). Enhancing working memory training with transcranial direct current stimulation. J. Cogn. Neurosci. 28, 1419-1432. doi: 10.1162/jocn_a_00979

Bäckman, L., Karlsson, S., Fischer, H., Karlsson, P., Brehmer, Y., Rieckmann, A., et al. (2011a). Dopamine $\mathrm{D}(1)$ receptors and age differences in brain activation during working memory. Neurobiol. Aging 32, 1849-1856. doi: 10.1016/j.neurobiolaging.2009.10.018

Bäckman, L., Lindenberger, U., Li, S. C., and Nyberg, L. (2010). Linking cognitive aging to alterations in dopamine neurotransmitter functioning: recent data and future avenues. Neurosci. Biobehav. Rev. 34, 670-677. doi: 10.1016/j.neubiorev.2009.12.008

Bäckman, L., Nyberg, L., Soveri, A., Johansson, J., Andersson, M., Dahlin, E., et al. (2011b). Effects of working-memory training on striatal dopamine release. Science 333:718. doi: 10.1126/science. 1204978

Ball, K., Berch, D. B., Helmers, K. F., Jobe, J. B., Leveck, M. D., Marsiske, M., et al. (2002). Effects of cognitive training interventions with older adults - A randomized controlled trial. J. Am. Med. Assoc. 288, 2271-2281. doi: 10.1001/jama.288.18.2271

Baltes, P. B. (1987). Theoretical propositions of life-span developmentalpsychology - on the dynamics between growth and decline. Dev. Psychol. 23, 611-626. doi: 10.1037/0012-1649.23.5.611

Baltes, P. B., Dittmann-Kohli, F., and Kliegl, R. (1986). Reserve capacity of the elderly in aging-sensitive tests of fluid intelligence: replication and extension. Psychol. Aging 1, 172.

Bamidis, P. D., Vivas, A. B., Styliadis, C., Frantzidis, C., Klados, M., Schlee, W., et al. (2014). A review of physical and cognitive interventions in aging. Neurosci. Biobehav. Rev. 44, 206-220. doi: 10.1016/j.neubiorev.2014.03.019

Barnes, C. A., and McNaughton, B. L. (1985). An age comparison of the rates of acquisition and forgetting of spatial information in relation to long-term enhancement of hippocampal synapses.
SP, FT, and SL agree to be accountable for all aspects of the work in ensuring that questions related to the accuracy or integrity of any part of the work are appropriately investigated and resolved.

\section{ACKNOWLEDGMENTS}

The work was supported by the Deutsche Forschungsgemeinschaft (DFG) through the Collaborative Research Center (SFB 940/2 "Volition and Cognitive Control: Mechanisms, Modulators, and Dysfunction") Project B3 (PIs: SL, FT, Michael Smolka) as well as a grant to SL (LI 879/18-1) and SP (PA 2972/1-1). Further support was provided by a grant to SL (FZK 01GQ1424D) of the Bundesministerium für Bildung und Forschung (BMBF). In addition, we acknowledge support by the Open Access Publication Funds of the TU Dresden.
Behav. Neurosci. 99, 1040-1048. doi: 10.1037/0735-7044.99. 6.1040

Barnes, C. A., Rao, G., and Houston, F. P. (2000). LTP induction threshold change in old rats at the perforant path-granule cell synapse. Neurobiol. Aging 21 , 613-620. doi: 10.1016/s0197-4580(00)00163-9

Barnes, C. A., Treves, A., Rao, G., and Shen, J. (1994). Electrophysiological markers of cognitive aging - region specificity and computational consequences. Semin. Neurosci. 6, 359-367. doi: 10.1006/smns.1994.1047

Bavelier, D., Green, C. S., Pouget, A., and Schrater, P. (2012). Brain plasticity through the life span: learning to learn and action video games. Annu. Rev. Neurosci. 35, 391-416. doi: 10.1146/annurev-neuro-060909-152832

Bennabi, D., Pedron, S., Haffen, E., Monnin, J., Peterschmitt, Y., and Van Waes, V. (2014). Transcranial direct current stimulation for memory enhancement: from clinical research to animal models. Front. Syst. Neurosci. 8:159. doi: 10.3389/fnsys.2014.00159

Berryhill, M. E., and Jones, K. T. (2012). tDCS selectively improves working memory in older adults with more education. Neurosci. Lett. 521, 148-151. doi: 10.1016/j.neulet.2012.05.074

Berryhill, M. E., Wencil, E. B., Branch Coslett, H., and Olson, I. R. (2010). A selective working memory impairment after transcranial direct current stimulation to the right parietal lobe. Neurosci. Lett. 479, 312-316. doi: 10.1016/j.neulet.2010.05.087

Bethus, I., Tse, D., and Morris, R. G. (2010). Dopamine and memory: modulation of the persistence of memory for novel hippocampal NMDA receptor-dependent paired associates. J. Neurosci. 30, 1610-1618. doi: 10.1523/JNEUROSCI.2721-09.2010

Boggio, P. S., Khoury, L. P., Martins, D. C., Martins, O. E., de Macedo, E. C., and Fregni, F. (2009). Temporal cortex direct current stimulation enhances performance on a visual recognition memory task in Alzheimer disease. J. Neurol. Neurosurg. Psychiatr. 80, 444-447. doi: 10.1136/jnnp.2007.141853

Bohbot, V. D., McKenzie, S., Konishi, K., Fouquet, C., Kurdi, V., Schachar, R., et al. (2012). Virtual navigation strategies from childhood to senescence: evidence for changes across the life span. Front. Aging Neurosci. 4:28. doi: 10.3389/fnagi.2012.00028

Bopp, K. L., and Verhaeghen, P. (2005). Aging and verbal memory span: a meta-analysis. J. Gerontol. B Psychol. Sci. Soc. Sci. 60, P223-P233. doi: 10.1093/geronb/60.5.P223

Borella, E., Carretti, B., and De Beni, R. (2008). Working memory and inhibition across the adult life-span. Acta Psychol. 128, 33-44. doi: 10.1016/j.actpsy.2007.09.008

Borella, E., Carretti, B., Riboldi, F., and De Beni, R. (2010). Working memory training in older adults evidence of transfer and maintenance effects. Psychol. Aging 25, 767-778. doi: 10.1037/a0020683

Braver, T. S., and Cohen, J. D. (2000). "On the control of control: the role of dopamine in regulating prefrontal function and working memory," in Attention 
and Performance XVIII, eds S. Monsell and J. Driver (Cambridge, MA: MIT Press), 713-737.

Brehmer, Y., Kalpouzos, G., Wenger, E., and Lövdén, M. (2014). Plasticity of brain and cognition in older adults. Psychol. Res. Psychol. Forsch. 78, 790-802. doi: 10.1007/s00426-014-0587-Z

Brehmer, Y., Li, S.-C., Müller, V., von Oertzen, T., and Lindenberger, U. (2007). Memory plasticity across the life span: uncovering children's latent potential. Dev. Psychol. 43, 465-478. doi: 10.1037/0012-1649.43.2.465

Brehmer, Y., Rieckmann, A., Bellander, M., Westerberg, H., Fischer, H., and Bäckman, L. (2011). Neural correlates of training-related working-memory gains in old age. Neuroimage 58, 1110-1120. doi: 10.1016/j.neuroimage.2011.06.079

Brehmer, Y., Westerberg, H., and Bäckman, L. (2012). Working-memory training in younger and older adults: training gains, transfer, and maintenance. Front. Hum. Neurosci. 6:63. doi: 10.3389/fnhum.2012.00063

Brozoski, T. J., Brown, R. M., Rosvold, H. E., and Goldman, P. S. (1979). Cognitive deficit caused by regional depletion of dopamine in prefrontal cortex of rhesusmonkey. Science 205, 929-932. doi: 10.1126/science.112679

Brunoni, A. R., and Vanderhasselt, M. A. (2014). Working memory improvement with non-invasive brain stimulation of the dorsolateral prefrontal cortex: a systematic review and meta-analysis. Brain Cogn. 86, 1-9. doi: 10.1016/j.bandc.2014.01.008

Brunyé, T. T., Holmes, A., Cantelon, J., Eddy, M. D., Gardony, A. L., Mahoney, C. R., et al. (2014). Direct current brain stimulation enhances navigation efficiency in individuals with low spatial sense of direction. Neuroreport 25, 1175-1179. doi: 10.1097/WNR.0000000000000214

Buschkuehl, M., Jaeggi, S. M., Hutchison, S., Perrig-Chiello, P., Däpp, C., Muller, M., et al. (2008). Impact of working memory training on memory performance in old-old adults. Psychol. Aging 23, 743-753. doi: 10.1037/a0014342

Cabeza, R., Anderson, N. D., Houle, S., Mangels, J. A., and Nyberg, L. (2000). Agerelated differences in neural activity during item and temporal-order memory retrieval: a positron emission tomography study. J. Cogn. Neurosci. 12, 197-206. doi: 10.1162/089892900561832

Cabeza, R., Daselaar, S. M., Dolcos, F., Prince, S. E., Budde, M., and Nyberg, L. (2004). Task-independent and task-specific age effects on brain activity during working memory, visual attention and episodic retrieval. Cereb. Cortex 14, 364-375. doi: 10.1093/cercor/bhg133

Cano-Colino, M., Almeida, R., Gomez-Cabrero, D., Artigas, F., and Compte, A. (2014). Serotonin regulates performance nonmonotonically in a spatial working memory network. Cereb. Cortex 24, 2449-2463. doi: 10.1093/cercor/bht096

Chalfonte, B. L., and Johnson, M. K. (1996). Feature memory and binding in young and older adults. Mem. Cogn. 24, 403-416. doi: 10.3758/bf03200930

Chein, J. M., and Morrison, A. B. (2010). Expanding the mind's workspace: training and transfer effects with a complex working memory span task. Psychon. Bull. Rev. 17, 193-199. doi: 10.3758/pbr.17.2.193

Cho, S. S., and Strafella, A. P. (2009). rTMS of the left dorsolateral prefrontal cortex modulates dopamine release in the ipsilateral anterior cingulate cortex and orbitofrontal cortex. PLoS ONE 4:e6725. doi: 10.1371/journal.pone.0006725

Chowdhury, R., Guitart-Masip, M., Bunzeck, N., Dolan, R. J., and Düzel, E. (2012). Dopamine modulates episodic memory persistence in old age. J. Neurosci. 32, 14193-14204. doi: 10.1523/JNEUROSCI.1278-12.2012

Collins, P., Roberts, A. C., Dias, R., Everitt, B. J., and Robbins, T. W. (1998). Perseveration and strategy in a novel spatial self-ordered sequencing task for nonhuman primates: effects of excitotoxic lesions and dopamine depletions of the prefrontal cortex. J. Cogn. Neurosci. 10, 332-354. doi: 10.1162/089892998562771

Constantinidis, C., and Klingberg, T. (2016). The neuroscience of working memory capacity and training. Nat. Rev. Neurosci. 17, 438-449. doi: 10.1038/nrn.2016.43

Cools, R., and D'Esposito, M. (2011). Inverted-U-shaped dopamine actions on human working memory and cognitive control. Biol. Psychiatry 69, e113-e125. doi: 10.1016/j.biopsych.2011.03.028.

Cools, R., Gibbs, S. E., Miyakawa, A., Jagust, W., and D’Esposito, M. (2008). Working memory capacity predicts dopamine synthesis capacity in the human striatum. J. Neurosci. 28, 1208-1212. doi: 10.1523/JNEUROSCI.4475-07.2008

Cotelli, M., Manenti, R., Brambilla, M., Petesi, M., Rosini, S., Ferrari, C., et al. (2014). Anodal tDCS during face-name associations memory training in Alzheimer's patients. Front. Aging Neurosci. 6:38. doi: 10.3389/fnagi.2014.00038
Cowan, N., Elliott, E. M., Saults, J. S., Morey, C. C., Mattox, S., Hismjatullina, A., et al. (2005). On the capacity of attention: its estimation and its role in working memory and cognitive aptitudes. Cogn. Psychol. 51, 42-100. doi: 10.1016/j.cogpsych.2004.12.001

Craik, F. I., Winocur, G., Palmer, H., Binns, M. A., Edwards, M., Bridges, K., et al. (2007). Cognitive rehabilitation in the elderly: effects on memory. J. Int. Neuropsychol. Soc. 13, 132-142. doi: 10.1017/S1355617707070166

Dahlin, E., Neely, A. S., Larsson, A., Bäckman, L., and Nyberg, L. (2008a). Transfer of learning after updating training mediated by the striatum. Science 320 , 1510-1512. doi: 10.1126/science.1155466

Dahlin, E., Nyberg, L., Bäckman, L., and Neely, A. S. (2008b). Plasticity of executive functioning in young and older adults: immediate training gains, transfer, and long-term maintenance. Psychol. Aging 23, 720-730. doi: 10.1037/a0014296

D’Ardenne, K., Eshel, N., Luka, J., Lenartowicz, A., Nystrom, L. E., and Cohen, J. D. (2012). Role of prefrontal cortex and the midbrain dopamine system in working memory updating. Proc. Natl. Acad. Sci. U.S.A. 109, 19900-19909. doi: $10.1073 /$ pnas.1116727109

Darki, F., and Klingberg, T. (2015). The role of fronto-parietal and fronto-striatal networks in the development of working memory: a longitudinal study. Cereb. Cortex 25, 1587-1595. doi: 10.1093/cercor/bht352

Dayan, P., and Huys, Q. J. (2009). Serotonin in affective control. Annu. Rev. Neurosci. 32, 95-126. doi: 10.1146/annurev.neuro.051508.135607

De Nigris, A., Piccardi, L., Bianchini, F., Palermo, L., Incoccia, C., and Guariglia, C. (2013). Role of visuo-spatial working memory in path integration disorders in neglect. Cortex 49, 920-930. doi: 10.1016/j.cortex.2012.03.009

D’Esposito, M. (2007). From cognitive to neural models of working memory. Philos. Trans. R. Soc. B Biol. Sci. 362, 761-772. doi: 10.1098/rstb.2007.2086

Doeller, C. F., King, J. A., and Burgess, N. (2008). Parallel striatal and hippocampal systems for landmarks and boundaries in spatial memory. Proc. Natl. Acad. Sci. U.S.A. 105, 5915-5920. doi: 10.1073/pnas.0801489105

Driscoll, I., Hamilton, D. A., Yeo, R. A., Brooks, W. M., and Sutherland, R. J. (2005). Virtual navigation in humans: the impact of age, sex, and hormones on place learning. Horm. Behav. 47, 326-335. doi: 10.1016/j.yhbeh.2004.11.013

Durstewitz, D., and Seamans, J. K. (2008). The dual-state theory of prefrontal cortex dopamine function with relevance to Catechol-OMethyltransferase genotypes and schizophrenia. Biol. Psychiatry 64, 739-749. doi: 10.1016/j.biopsych.2008.05.015

Durstewitz, D., Seamans, J. K., and Sejnowski, T. J. (2000a). Dopamine-mediated stabilization of delay-period activity in a network model of prefrontal cortex. J. Neurophysiol. 83, 1733-1750.

Durstewitz, D., Seamans, J. K., and Sejnowski, T. J. (2000b). Neurocomputational models of working memory. Nat. Neurosci. 3, 1184-1191. doi: 10.1038/81460

Ellis, J. R., Nathan, P. J., Villemagne, V. L., Mulligan, R. S., Ellis, K. A., TochonDanguy, H. J., et al. (2009). The relationship between nicotinic receptors and cognitive functioning in healthy aging: an in vivo Positron Emission Tomography (PET) study with 2- F-18 fluoro-A-85380. Synapse 63, 752-763. doi: $10.1002 /$ syn.20642

Ellis, K. A., and Nathan, P. J. (2001). The pharmacology of human working memory. Int. J. Neuropsychopharmacol. 4, 299-313. doi: 10.1017/S1461145701002541

Engle, R. W. (2002). Working memory capacity as executive attention. Curr. Dir. Psychol. Sci. 11, 19-23. doi: 10.1111/1467-8721.00160

Engvig, A., Fjell, A. M., Westlye, L. T., Moberget, T., Sundseth, Ø., Larsen, V. A., et al. (2010). Effects of memory training on cortical thickness in the elderly. Neuroimage 52, 1667-1676. doi: 10.1016/j.neuroimage.2010.05.041

Engvig, A., Fjell, A. M., Westlye, L. T., Skaane, N. V., Dale, A. M., Holland, D., et al. (2014). Effects of cognitive training on gray matter volumes in memory clinic patients with subjective memory impairment. J. Alzheimers Dis. 41, 779-791. doi: $10.3233 /$ jad-131889

Engvig, A., Fjell, A. M., Westlye, L. T., Skaane, N. V., Sundseth, Ø., and Walhovd, K. B. (2012). Hippocampal subfield volumes correlate with memory training benefit in subjective memory impairment. Neuroimage 61, 188-194. doi: 10.1016/j.neuroimage.2012.02.072

Erickson, K. I., Voss, M. W., Prakash, R. S., Basak, C., Szabo, A., Chaddock, L., et al. (2011). Exercise training increases size of hippocampus and improves memory. Proc. Natl. Acad. Sci. U.S.A. 108, 3017-3022. doi: 10.1073/pnas.1015950108

Etchamendy, N., Konishi, K., Pike, G. B., Marighetto, A., and Bohbot, V. D. (2012). Evidence for a virtual human analog of a rodent relational memory 
task: a study of aging and fMRI in young adults. Hippocampus 22, 869-880. doi: 10.1002/hipo.20948

Ferrucci, R., Mameli, F., Guidi, I., Mrakic-Sposta, S., Vergari, M., Marceglia, S., et al. (2008). Transcranial direct current stimulation improves recognition memory in Alzheimer disease. Neurology 71, 493-498. doi: 10.1212/01.wnl.0000317060.43722.a3

Fertonani, A., Brambilla, M., Cotelli, M., and Miniussi, C. (2014). The timing of cognitive plasticity in physiological aging: a tDCS study of naming. Front. Aging Neurosci. 6:131. doi: 10.3389/fnagi.2014.00131

Filmer, H. L., Dux, P. E., and Mattingley, J. B. (2014). Applications of transcranial direct current stimulation for understanding brain function. Trends Neurosci. 37, 742-753. doi: 10.1016/j.tins.2014.08.003

Flöel, A., and Cohen, L. G. (2010). Recovery of function in humans: cortical stimulation and pharmacological treatments after stroke. Neurobiol. Dis. 37, 243-251. doi: 10.1016/j.nbd.2009.05.027

Flöel, A., Suttorp, W., Kohl, O., Kürten, J., Lohmann, H., Breitenstein, C., et al. (2012). Non-invasive brain stimulation improves objectlocation learning in the elderly. Neurobiol. Aging 33, 1682-1689. doi: 10.1016/j.neurobiolaging.2011.05.007

Frank, M. J., Loughry, B., and O’Reilly, R. C. (2001). Interactions between frontal cortex and basal ganglia in working memory: a computational model. Cogn. Affect. Behav. Neurosci. 1, 137-160. doi: 10.3758/cabn.1.2.137

Fresnoza, S., Paulus, W., Nitsche, M. A., and Kuo, M. F. (2014a). Nonlinear dose-dependent impact of D1 receptor activation on motor cortex plasticity in humans. J. Neurosci. 34, 2744-2753. doi: 10.1523/jneurosci.3655-13.2014

Fresnoza, S., Stiksrud, E., Klinker, F., Liebetanz, D., Paulus, W., Kuo, M. F., et al. (2014b). Dosage-dependent effect of dopamine D2 receptor activation on motor cortex plasticity in humans. J. Neurosci. 34, 10701-10709. doi: 10.1523/JNEUROSCI.0832-14.2014

Fukuda, K., Vogel, E., Mayr, U., and Awh, E. (2010). Quantity, not quality: the relationship between fluid intelligence and working memory capacity. Psychon. Bull. Rev. 17, 673-679. doi: 10.3758/17.5.673

Geinisman, Y., de Toledo-Morrell, L., Morrell, F., Persina, I. S., and Rossi, M. (1992). Age-related loss of axospinous synapses formed by two afferent systems in the rat dentate gyrus as revealed by the unbiased stereological dissector technique. Hippocampus 2, 437-444.

Giovanello, K. S., and Schacter, D. L. (2012). Reduced specificity of hippocampal and posterior ventrolateral prefrontal activity during relational retrieval in normal aging. J. Cogn. Neurosci. 24, 159-170. doi: 10.1162/jocn_a_00113

Goldman-Rakic, P. S. (1996). Regional and cellular fractionation of working memory. Proc. Natl. Acad. Sci. U.S.A. 93, 13473-13480. doi: $10.1073 /$ pnas.93.24.13473

Grady, C. L., McIntosh, A. R., Bookstein, F., Horwitz, B., Rapoport, S. I., and Haxby, J. V. (1998). Age-related changes in regional cerebral blood flow during working memory for faces. Neuroimage 8, 409-425. doi: 10.1006/nimg.1998.0376

Gray, S. J., Brookshire, G., Casasanto, D., and Gallo, D. A. (2015). Electrically stimulating prefrontal cortex at retrieval improves recollection accuracy. Cortex 73, 188-194. doi: 10.1016/j.cortex.2015.09.003

Hampson, M., Driesen, N., Roth, J. K., Gore, J. C., and Constable, R. T. (2010). Functional connectivity between task-positive and task-negative brain areas and its relation to working memory performance. Magn. Reson. Imaging 28, 1051-1057. doi: 10.1016/j.mri.2010.03.021

Hampstead, B. M., Brown, G. S., and Hartley, J. F. (2014). Transcranial direct current stimulation modulates activation and effective connectivity during spatial navigation. Brain Stimul. 7, 314-324. doi: 10.1016/j.brs.2013.12.006

Harper, S. (2014). Economic and social implications of aging societies. Science 346, 587-591. doi: 10.1126/science. 1254405

Harris, M. A., Wiener, J. M., and Wolbers, T. (2012). Aging specifically impairs switching to an allocentric navigational strategy. Front. Aging Neurosci. 4:29. doi: 10.3389/fnagi.2012.00029

Hartley, T., Burgess, N., Lever, C., Cacucci, F., and O'Keefe, J. (2000). Modeling place fields in terms of the cortical inputs to the hippocampus. Hippocampus 10, 369-379. doi: 10.1002/1098-1063(2000)10:4<369::aid-hipo3>3.0.co;2-0

Hartley, T., Maguire, E. A., Spiers, H. J., and Burgess, N. (2003). The well-worn route and the path less traveled: distinct neural bases of route following and wayfinding in humans. Neuron 37, 877-888. doi: 10.1016/s0896-6273(03)00095-3
Hasselmo, M. E., and Stern, C. E. (2006). Mechanisms underlying working memory for novel information. Trends Cogn. Sci. 10, 487-493. doi: 10.1016/j.tics.2006.09.005

Hsu, W. Y., Ku, Y., Zanto, T. P., and Gazzaley, A. (2015). Effects of noninvasive brain stimulation on cognitive function in healthy aging and Alzheimer's disease: a systematic review and meta-analysis. Neurobiol. Aging 36, 2348-2359. doi: 10.1016/j.neurobiolaging.2015.04.016

Iaria, G., Petrides, M., Dagher, A., Pike, B., and Bohbot, V. D. (2003). Cognitive strategies dependent on the hippocampus and caudate nucleus in human navigation: Variability and change with practice. J. Neurosci. 23, 5945-5952.

Ibarra, G. R., Rodriguez, J. A., Paratcha, G. C., and Azcurra, J. M. (1995). Permanent alteration of muscarinic acetylcholine receptor binding in rat striatum after circling training during development. Brain Res. 705, 39-44. doi: 10.1016/0006-8993(95)01076-9

Islam, N., Aftabuddin, M., Moriwaki, A., Hattori, Y., and Hori, Y. (1995). Increase in the calcium level following anodal polarization in the rat-brain. Brain Res. 684, 206-208. doi: 10.1016/0006-8993(95)00434-r

Jaeggi, S. M., Buschkuehl, M., Jonides, J., and Perrig, W. J. (2008). Improving fluid intelligence with training on working memory. Proc. Natl. Acad. Sci. U.S.A. 105, 6829-6833. doi: 10.1073/pnas.0801268105

Javadi, A. H., and Walsh, V. (2012). Transcranial direct current stimulation (tDCS) of the left dorsolateral prefrontal cortex modulates declarative memory. Brain Stimul. 5, 231-241. doi: 10.1016/j.brs.2011.06.007

Jennings, J. M., Webster, L. M., Kleykamp, B. A., and Dagenbach, D. (2005). Recollection training and transfer effects in older adults: successful use of a repetition-lag procedure. Neuropsychol. Dev. Cogn. B Aging Neuropsychol. Cogn. 12, 278-298. doi: 10.1080/138255890968312

Jolles, D. D., van Buchem, M. A., Crone, E. A., and Rombouts, S. A. (2013). Functional brain connectivity at rest changes after working memory training. Hum. Brain Mapp. 34, 396-406. doi: 10.1002/hbm.21444

Jones, K. T., and Berryhill, M. E. (2012). Parietal contributions to visual working memory depend on task difficulty. Front. Psychiatry 3:81. doi: 10.3389/fpsyt.2012.00081

Jones, K. T., Gözenman, F., and Berryhill, M. E. (2014). Enhanced longterm memory encoding after parietal neurostimulation. Exp. Brain Res. 232, 4043-4054. doi: 10.1007/s00221-014-4090-y

Jones, K. T., Gözenman, F., and Berryhill, M. E. (2015a). The strategy and motivational influences on the beneficial effect of neurostimulation: a tDCS and fNIRS study. Neuroimage 105, 238-247. doi: 10.1016/j.neuroimage.2014. 11.012

Jones, K. T., Stephens, J. A., Alam, M., Bikson, M., and Berryhill, M. E. (2015b). Longitudinal neurostimulation in older adults improves working memory. PLoS ONE 10:e121904. doi: 10.1371/journal.pone.0121904

Kalus, P., Slotboom, J., Gallinat, J., Mahlberg, R., Cattapan-Ludewig, K., Wiest, R., et al. (2006). Examining the gateway to the limbic system with diffusion tensor imaging: the perforant pathway in dementia. Neuroimage 30, 713-720. doi: 10.1016/j.neuroimage.2005.10.035

Karbach, J., and Verhaeghen, P. (2014). Making working memory work: a metaanalysis of executive-control and working memory training in older adults. Psychol. Sci. 25, 2027-2037. doi: 10.1177/0956797614548725

Karreman, M., and Moghaddam, B. (1996). The prefrontal cortex regulates the basal release of dopamine in the limbic striatum: an effect mediated by ventral tegmental area. J. Neurochem. 66, 589-598.

Keck, M. E., Welt, T., Müller, M. B., Erhardt, A., Ohl, F., Toschi, N., et al. (2002). Repetitive transcranial magnetic stimulation increases the release of dopamine in the mesolimbic and mesostriatal system. Neuropharmacology 43, 101-109. doi: 10.1016/s0028-3908(02)00069-2

Keeser, D., Meindl, T., Bor, J., Palm, U., Pogarell, O., Mulert, C., et al. (2011). Prefrontal transcranial direct current stimulation changes connectivity of resting-state networks during fMRI. J. Neurosci. 31, 15284-15293. doi: 10.1523/JNEUROSCI.0542-11.2011

Kellendonk, C., Simpson, E. H., Polan, H. J., Malleret, G., Vronskaya, S., Winiger, V., et al. (2006). Transient and selective overexpression of dopamine D2 receptors in the striatum causes persistent abnormalities in prefrontal cortex functioning. Neuron 49, 603-615. doi: 10.1016/j.neuron.2006.01.023

Kentros, C. G., Agnihotri, N. T., Streater, S., Hawkins, R. D., and Kandel, E. R. (2004). Increased attention to spatial context increases both place field stability and spatial memory. Neuron 42, 283-295. doi: 10.1016/S0896-6273(04)00192-8 
Kishore, A., Popa, T., James, P., Yahia-Cherif, L., Backer, F., Chacko, L. V., et al. (2014). Age-related decline in the responsiveness of motor cortex to plastic forces reverses with levodopa or cerebellar stimulation. Neurobiol. Aging 35, 2541-2551. doi: 10.1016/j.neurobiolaging.2014.05.004

Klostermann, E. C., Braskie, M. N., Landau, S. M., O’Neil, J. P., and Jagust, W. J. (2012). Dopamine and frontostriatal networks in cognitive aging. Neurobiol. Aging 623 e615-624. doi: 10.1016/j.neurobiolaging.2011.03.002

Kolachana, B. S., Saunders, R. C., and Weinberger, D. R. (1995). Augmentation of prefrontal cortical monoaminergic activity inhibits dopamine release in the caudate-nucleus - an in-vivo neurochemical assessment in the rhesus-monkey. Neuroscience 69, 859-868. doi: 10.1016/0306-4522(95)00246-f

Konishi, K., and Bohbot, V. D. (2013). Spatial navigational strategies correlate with gray matter in the hippocampus of healthy older adults tested in a virtual maze. Front. Aging Neurosci. 5:1. doi: 10.3389/fnagi.2013.00001

Krishnamurthy, V., Gopinath, K., Brown, G. S., and Hampstead, B. M. (2015). Resting-state fMRI reveals enhanced functional connectivity in spatial navigation networks after transcranial direct current stimulation. Neurosci. Lett. 604, 80-85. doi: 10.1016/j.neulet.2015.07.042

Kühn, S., Schmiedek, F., Noack, H., Wenger, E., Bodammer, N. C., Lindenberger, U., et al. (2013). The dynamics of change in striatal activity following updating training. Hum. Brain Mapp. 34, 1530-1541. doi: 10.1002/hbm. 22007

Kuo, M. F., and Nitsche, M. A. (2015). Exploring prefrontal cortex functions in healthy humans by transcranial electrical stimulation. Neurosci. Bull. 31, 198-206. doi: 10.1007/s12264-014-1501-9

Kuo, M. F., Paulus, W., and Nitsche, M. A. (2008). Boosting focally-induced brain plasticity by dopamine. Cereb. Cortex 18, 648-651. doi: 10.1093/cercor/bhm098

Landau, S. M., Lal, R., O’Neil, J. P., Baker, S., and Jagust, W. J. (2009). Striatal dopamine and working memory. Cereb. Cortex 19, 445-454. doi: 10.1093/cercor/bhn095

Landfield, P. W., McGaugh, J. L., and Lynch, G. (1978). Impaired synaptic potentiation processes in the hippocampus of aged, memory-deficient rats. Brain Res. 150, 85-101.

Learmonth, G., Thut, G., Benwell, C. S., and Harvey, M. (2015). The implications of state-dependent tDCS effects in aging: behavioural response is determined by baseline performance. Neuropsychologia 74, 108-119. doi: 10.1016/j.neuropsychologia.2015.01.037

Leshikar, E. D., Gutchess, A. H., Hebrank, A. C., Sutton, B. P., and Park, D. C. (2010). The impact of increased relational encoding demands on frontal and hippocampal function in older adults. Cortex 46, 507-521. doi: 10.1016/j.cortex.2009.07.011

Li, S.-C., Lindenberger, U., and Sikström, S. (2001). Aging cognition: from neuromodulation to representation. Trends Cogn. Sci. 5, 479-486. doi: 10.1016/s1364-6613(00)01769-1

Li, S.-C., Naveh-Benjamin, M., and Lindenberger, U. (2005). Aging neuromodulation impairs associative binding neurocomputational account. Psychol. Sci. 16, 445-450. doi: 10.1111/j.0956-7976.2005.01555.x

Li, S.-C., Papenberg, G., Nagel, I. E., Preuschhof, C., Schröder, J., Nietfeld, W., et al. (2013). Aging magnifies the effects of dopamine transporter and D2 receptor genes on backward serial memory. Neurobiol. Aging 34, 358.e1-358.e10. doi: 10.1016/j.neurobiolaging.2012.08.001

Li, S.-C., and Rieckmann, A. (2014). Neuromodulation and aging: implications of aging neuronal gain control on cognition. Curr. Opin. Neurobiol. 29, 148-158. doi: 10.1016/j.conb.2014.07.009

Li, S.-C., Schmiedek, F., Huxhold, O., Röcke, C., Smith, J., and Lindenberger, U. (2008). Working memory plasticity in old age: practice gain, transfer, and maintenance. Psychol. Aging 23, 731-742. doi: 10.1037/a0014343

Li, S.-C., and Sikström, S. (2002). Integrative neurocomputational perspectives on cognitive aging, neuromodulation, and representation. Neurosci. Biobehav. Rev. 26, 795-808. doi: 10.1016/s0149-7634(02)00066-0

Liebetanz, D., Nitsche, M. A., Tergau, F., and Paulus, W. (2002). Pharmacological approach to the mechanisms of transcranial DC-stimulation-induced after-effects of human motor cortex excitability. Brain 125, 2238-2247. doi: 10.1093/brain/awf238

Linden, D. E. (2007). The working memory networks of the human brain. Neuroscientist 13, 257-267. doi: 10.1177/1073858406298480

Lindenberger, U. (2014). Human cognitive aging: corriger la fortune? Science 346, 572-578. doi: 10.1126/science. 1254403
Lisman, J. E., and Grace, A. A. (2005). The hippocampal-VTA loop: controlling the entry of information into long-term memory. Neuron 46, 703-713. doi: 10.1016/j.neuron.2005.05.002

Logan, J. M., Sanders, A. L., Snyder, A. Z., Morris, J. C., and Buckner, R. L. (2002). Under-recruitment and nonselective recruitment: dissociable neural mechanisms associated with aging. Neuron 33, 827-840. doi: 10.1016/s0896-6273(02)00612-8

Looi, C. Y., Duta, M., Brem, A. K., Huber, S., Nuerk, H. C., and Cohen Kadosh, R. (2016). Combining brain stimulation and video game to promote longterm transfer of learning and cognitive enhancement. Sci. Rep. 6:22003. doi: $10.1038 /$ srep 22003

Lövdén, M., Bäckman, L., Lindenberger, U., Schaefer, S., and Schmiedek, F. (2010). A theoretical framework for the study of adult cognitive plasticity. Psychol. Bull. 136, 659-676. doi: 10.1037/a0020080

Lövdén, M., Schaefer, S., Noack, H., Bodammer, N. C., Kühn, S., Heinze, H. J., et al. (2012). Spatial navigation training protects the hippocampus against age-related changes during early and late adulthood. Neurobiol. Aging 33, 620.e9-620.e22. doi: 10.1016/j.neurobiolaging.2011.02.013

Lövdén, M., Schaefer, S., Noack, H., Kanowski, M., Kaufmann, J., Tempelmann, C., et al. (2011). Performance-related increases in hippocampal N-acetylaspartate (NAA) induced by spatial navigation training are restricted to BDNF Val homozygotes. Cereb. Cortex 21, 1435-1442. doi: 10.1093/cercor/bhq230

Luciana, M., Collins, P. F., and Depue, R. A. (1998). Opposing roles for dopamine and serotonin in the modulation of human spatial working memory functions. Cereb. Cortex 8, 218-226. doi: 10.1093/cercor/8.3.218

Lustig, C., and Flegal, K. E. (2008). Targeting latent function: encouraging effective encoding for successful memory training and transfer. Psychol. Aging 23, 754-764. doi: 10.1037/a0014295

MacRae, P. G., Spirduso, W. W., Walters, T. J., Farrar, R. P., and Wilcox, R. E. (1987). Endurance training effects on striatal d2-dopamine receptorbinding and striatal dopamine metabolites in presenescent older rats. Psychopharmacology 92, 236-240.

Madden, D. J., Turkington, T. G., Provenzale, J. M., Denny, L. L., Hawk, T. C., Gottlob, L. R., et al. (1999). Adult age differences in the functional neuroanatomy of verbal recognition memory. Hum. Brain Mapp. 7, 115-135. doi: 10.1002/(sici)1097-0193(1999)7:2<115::aid-hbm5>3.0.co;2-n

Mancuso, L. E., Ilieva, I. P., Hamilton, R. H., and Farah, M. J. (2016). Does transcranial direct current stimulation improve healthy working memory?: a meta-analytic review. J. Cogn. Neurosci. 28, 1063-1089. doi: 10.1162/jocn_a_00956

Manenti, R., Brambilla, M., Petesi, M., Ferrari, C., and Cotelli, M. (2013). Enhancing verbal episodic memory in older and young subjects after non-invasive brain stimulation. Front. Aging Neurosci. 5:49. doi: $10.3389 /$ fnagi.2013.00049

McDonald, R. J., and White, N. M. (1994). Parallel information-processing in the water maze - evidence for independent memory-systems involving dorsal striatum and hippocampus. Behav. Neural Biol. 61, 260-270. doi: 10.1016/s0163-1047(05)80009-3

McNab, F., and Klingberg, T. (2008). Prefrontal cortex and basal ganglia control access to working memory. Nat. Neurosci. 11, 103-107. doi: 10.1038/nn2024

McNab, F., Varrone, A., Farde, L., Jucaite, A., Bystritsky, P., Forssberg, H., et al. (2009). Changes in cortical dopamine D1 receptor binding associated with cognitive training. Science 323, 800-802. doi: 10.1126/science.1166102

Meinzer, M., Antonenko, D., Lindenberg, R., Hetzer, S., Ulm, L., Avirame, K., et al. (2012). Electrical brain stimulation improves cognitive performance by modulating functional connectivity and task-specific activation. J. Neurosci. 32, 1859-1866. doi: 10.1523/jneurosci.4812-11.2012

Meinzer, M., Jähnigen, S., Copland, D. A., Darkow, R., Grittner, U., Avirame, K., et al. (2014). Transcranial direct current stimulation over multiple days improves learning and maintenance of a novel vocabulary. Cortex 50, 137-147. doi: 10.1016/j.cortex.2013.07.013

Miller, E. K., and Wallis, J. D. (2009). "Executive function and higherorder cognition: Definition and neural substrates," in Encyclopedia of Neuroscience, 4thEdn., ed L. R. Squire (Oxford: Academic), 99-104.

Mitsis, E. A., Cosgrove, K. P., Staley, J. K., Bois, F., Frohlich, E. B., Tamagnan, G. D., et al. (2009). Age-related decline in nicotinic receptor availability with I-123 5-IA-85380 SPECT. Neurobiol. Aging 30, 1490-1497. doi: 10.1016/j.neurobiolaging.2007.12.008 
Miyoshi, E., Wietzikoski, E. C., Bortolanza, M., Boschen, S. L., Canteras, N. S., Izquierdo, I., et al. (2012). Both the dorsal hippocampus and the dorsolateral striatum are needed for rat navigation in the Morris water maze. Behav. Brain Res. 226, 171-178. doi: 10.1016/j.bbr.2011.09.011

Moffat, S. D., and Resnick, S. M. (2002). Effects of age on virtual environment place navigation and allocentric cognitive mapping. Behav. Neurosci. 116, 851-859. doi: 10.1037//0735-7044.116.5.851

Montague, P. R., Hyman, S. E., and Cohen, J. D. (2004). Computational roles for dopamine in behavioural control. Nature 431, 760-767. doi: $10.1038 /$ nature03015

Monte-Silva, K., Liebetanz, D., Grundey, J., Paulus, W., and Nitsche, M. A. (2010). Dosage-dependent non-linear effect of 1-dopa on human motor cortex plasticity. J. Physiol. 588, 3415-3424. doi: 10.1113/jphysiol.2010.1 90181

Moser, E. I., Kropff, E., and Moser, M.-B. (2008). Place cells, grid cells, and the brain's spatial representation system. Neuroscience 31:69. doi: 10.1146/annurev.neuro.31.061307.090723

Murphy, B. L., Arnsten, A. F., GoldmanRakic, P. S., and Roth, R. H. (1996). Increased dopamine turnover in the prefrontal cortex impairs spatial working memory performance in rats and monkeys. Proc. Natl. Acad. Sci. U.S.A. 93, 1325-1329. doi: 10.1073/pnas.93.3.1325

Naveh-Benjamin, M. (2000). Adult age differences in memory performance: tests of an associative deficit hypothesis. J. Exp. Psychol. Learn. Mem. Cogn. 26, 1170-1187. doi: 10.1037//0278-7393.26.2.1170

Nicholson, D. A., Yoshida, R., Berry, R. W., Gallagher, M., and Geinisman, Y. (2004). Reduction in size of perforated postsynaptic densities in hippocampal axospinous synapses and age-related spatial learning impairments. J. Neurosci. 24, 7648-7653. doi: 10.1523/JNEUROSCI.172504.2004

Nilsson, J., Lebedev, A. V., and Lövdén, M. (2015). No significant effect of prefrontal tDCS on working memory performance in older adults. Front. Aging Neurosci. 7:230. doi: 10.3389/fnagi.2015.00230

Nitsche, M. A., Lampe, C., Antal, A., Liebetanz, D., Lang, N., Tergau, F., et al. (2006). Dopaminergic modulation of long-lasting direct current-induced cortical excitability changes in the human motor cortex. Eur. J. Neurosci. 23, 1651-1657. doi: 10.1111/j.1460-9568.2006.04676.x

Nitsche, M. A., and Paulus, W. (2000). Excitability changes induced in the human motor cortex by weak transcranial direct current stimulation. J. Physiol. Lond. 527, 633-639. doi: 10.1111/j.1469-7793.2000.t01-1-0 0633.x

Nitsche, M. A., and Paulus, W. (2001). Sustained excitability elevations induced by transcranial DC motor cortex stimulation in humans. Neurology 57, 1899-1901. doi: 10.1212/WNL.57.10.1899

Noack, H., Lövdén, M., and Schmiedek, F. (2014). On the validity and generality of transfer effects in cognitive training research. Psychol. Res. 78, 773-789. doi: 10.1007/s00426-014-0564-6

Noack, H., Lövdén, M., Schmiedek, F., and Lindenberger, U. (2009). Cognitive plasticity in adulthood and old age: gauging the generality of cognitive intervention effects. Restor. Neurol. Neurosci. 27, 435-453. doi: 10.3233/rnn-2009-0496

Nord, M., Cselenyi, Z., Forsberg, A., Rosenqvist, G., Tiger, M., Lundberg, J., et al. (2014). Distinct regional age effects on C-11 AZ10419369 binding to 5-HT1B receptors in the human brain. Neuroimage 103, 303-308. doi: 10.1016/j.neuroimage.2014.09.040

Nyberg, L., Lövdén, M., Riklund, K., Lindenberger, U., and Bäckman, L. (2012). Memory aging and brain maintenance. Trends Cogn. Sci. 16, 292-305. doi: 10.1016/j.tics.2012.04.005

Nyberg, L., Sandblom, J., Jones, S., Neely, A. S., Petersson, K. M., Ingvar, M., et al. (2003). Neural correlates of training-related memory improvement in adulthood and aging. Proc. Natl. Acad. Sci. U.S.A. 100, 13728-13733. doi: $10.1073 /$ pnas. 1735487100

Ohn, S. H., Park, C. I., Yoo, W. K., Ko, M. H., Choi, K. P., Kim, G. M., et al. (2008). Time-dependent effect of transcranial direct current stimulation on the enhancement of working memory. Neuroreport 19, 43-47. doi: 10.1097/WNR.0b013e3282f2adfd

O'Keefe, J., and Burgess, N. (1996). Geometric determinants of the place fields of hippocampal neurons. Nature 381, 425-428.
O'Keefe, J., and Dostrovsky, J. (1971). The hippocampus as a spatial map. Preliminary evidence from unit activity in the freely-moving rat. Brain Res. 34, 171-175.

Old, S. R., and Naveh-Benjamin, M. (2008). Differential effects of age on item and associative measures of memory: a meta-analysis. Psychol. Aging 23, 104-118. doi: 10.1037/0882-7974.23.1.104

Olesen, P. J., Westerberg, H., and Klingberg, T. (2004). Increased prefrontal and parietal activity after training of working memory. Nat. Neurosci. 7, 75-79. doi: $10.1038 / \mathrm{nn} 1165$

Oswald, W. D., Gunzelmann, T., Rupprecht, R., and Hagen, B. (2006). Differential effects of single versus combined cognitive and physical training with older adults: the SimA study in a 5-year perspective. Eur. J. Ageing 3, 179-192. doi: 10.1007/s10433-006-0035-Z

Packard, M. G., Hirsh, R., and White, N. M. (1989). Differential effects of fornix and caudate nucleus lesions on two radial maze tasks: evidence for multiple memory systems. J. Neurosci. 9, 1465-1472.

Packard, M. G., and McGaugh, J. L. (1992). Double dissociation of fornix and caudate nucleus lesions on acquisition of two water maze tasks: further evidence for multiple memory systems. Behav. Neurosci. 106:439.

Papenberg, G., Bäckman, L., Nagel, I. E., Nietfeld, W., Schröder, J., Bertram, L., et al. (2013). Dopaminergic gene polymorphisms affect long-term forgetting in old age: further support for the magnification hypothesis. J. Cogn. Neurosci. 25, 571-579. doi: 10.1162/jocn_a_00359

Parasuraman, R., Greenwood, P., Scheldrup, M., Falcone, B., Kidwell, B., and McKendrick, R. (2014). Neuroergonomics of skill acquisition: genetic and noninvasive brain stimulation studies. Adv. Cogn. Eng. Neuroergonomics 11:73.

Lever, A. G., Werkle-Bergner, M., Brandmaier, A. M., Ridderinkhof, K. R., Geurts, H. M. (2006). “Working memory across the adult lifespan,” in Lifespan Cognition Mechanisms of Change, eds E. Bialystok and F. I. M. Craik (New York, NY: Oxford University Press), 128-142.

Park, S. H., Seo, J. H., Kim, Y. H., and Ko, M. H. (2014). Long-term effects of transcranial direct current stimulation combined with computerassisted cognitive training in healthy older adults. Neuroreport 25, 122-126. doi: 10.1097/WNR.0000000000000080

Pisoni, A., Turi, Z., Raithel, A., Ambrus, G. G., Alekseichuk, I., Schacht, A., et al. (2015). Separating recognition processes of declarative memory via anodal tDCS: boosting old item recognition by temporal and new item detection by parietal stimulation. PLoS ONE 10:e0123085. doi: 10.1371/journal.pone.0123085

Postle, B. R. (2006). Working memory as an emergent property of the mind and brain. Neuroscience 139, 23-38. doi: 10.1016/j.neuroscience.2005.06.005

Qi, X. L., and Constantinidis, C. (2012a). Correlated discharges in the primate prefrontal cortex before and after working memory training. Eur. J. Neurosci. 36, 3538-3548. doi: 10.1111/j.1460-9568.2012.08267.x

Qi, X. L., and Constantinidis, C. (2012b). Variability of prefrontal neuronal discharges before and after training in a working memory task. PLoS ONE 7:e41053. doi: 10.1371/journal.pone.0041053

Rajah, M. N., and D’Esposito, M. (2005). Region-specific changes in prefrontal function with age: a review of PET and fMRI studies on working and episodic memory. Brain 128, 1964-1983. doi: 10.1093/brain/awh608

Raz, N., Lindenberger, U., Rodrigue, K. M., Kennedy, K. M., Head, D., Williamson, A., et al. (2005). Regional brain changes in aging healthy adults: general trends, individual differences and modifiers. Cereb. Cortex 15, 1676-1689. doi: 10.1093/cercor/bhi044

Reis, J., Schambra, H. M., Cohen, L. G., Buch, E. R., Fritsch, B., Zarahn, E., et al. (2009). Noninvasive cortical stimulation enhances motor skill acquisition over multiple days through an effect on consolidation. Proc. Natl. Acad. Sci. U.S.A. 106, 1590-1595. doi: 10.1073/pnas.0805413106

Reuter-Lorenz, P. (2002). New visions of the aging mind and brain. Trends Cogn. Sci. 6, 394-400. doi: 10.1016/s1364-6613(02)01957-5

Richmond, L. L., Morrison, A. B., Chein, J. M., and Olson, I. R. (2011). Working memory training and transfer in older adults. Psychol. Aging 26, 813-822. doi: $10.1037 / \mathrm{a} 0023631$

Richmond, L. L., Wolk, D., Chein, J., and Olson, I. R. (2014). Transcranial direct current stimulation enhances verbal working memory training performance over time and near transfer outcomes. J. Cogn. Neurosci. 26, 2443-2454. doi: 10.1162/jocn_a_00657 
Richter, N., Allendorf, I., Onur, O. A., Kracht, L., Dietlein, M., Tittgemeyer, M., et al. (2014). The integrity of the cholinergic systemdetermines memory performance in healthy elderly. Neuroimage 100, 481-488. doi: 10.1016/j.neuroimage.2014.06.031

Rieckmann, A., Karlsson, S., Fischer, H., and Bäckman, L. (2011). Caudate dopamine D1 receptor density is associated with individual differences in frontoparietal connectivity during working memory. J. Neurosci. 31, 14284-14290. doi: 10.1523/JNEUROSCI.3114-11.2011

Roberts, A. C., De salvia, M. A., Wilkinson, L. S., Collins, P., Muir, J. L., Everitt, B. J., et al. (1994). 6-hydroxydopamine lesions of the prefrontal cortex in monkeys enhance performance on an analog of the wisconsin card sort test - possible interactions with subcortical dopamine. J. Neurosci. 14, 2531-2544.

Rodgers, M. K., Sindone, J. A. III., and Moffat, S. D. (2012). Effects of age on navigation strategy. Neurobiol. Aging 33, 202 e215-222. doi: 10.1016/j.neurobiolaging.2010.07.021

Rosenzweig, E. S., and Barnes, C. A. (2003). Impact of aging on hippocampal function: plasticity, network dynamics, and cognition. Prog. Neurobiol. 69, 143-179. doi: 10.1016/s0301-0082(02)00126-0

Rossato, J. I., Bevilaqua, L. R., Izquierdo, I., Medina, J. H., and Cammarota, M. (2009). Dopamine controls persistence of long-term memory storage. Science 325, 1017-1020. doi: 10.1126/science.1172545

Rowe, J. W., and Kahn, R. L. (1987). Human aging - usual and successful. Science 237, 143-149. doi: 10.1126/science.3299702

Rypma, B., and D'Esposito, M. (2000). Isolating the neural mechanisms of age-related changes in human working memory. Nat. Neurosci. 3, 509-515. doi: $10.1038 / 74889$

Sander, M. C., Lindenberger, U., and Werkle-Bergner, M. (2012). Lifespan age differences in working memory: a two-component framework. Neurosci. Biobehav. Rev. 36, 2007-2033. doi: 10.1016/j.neubiorev.2012.06.004

Sandrini, M., Brambilla, M., Manenti, R., Rosini, S., Cohen, L. G., and Cotelli, M. (2014). Noninvasive stimulation of prefrontal cortex strengthens existing episodic memories and reduces forgetting in the elderly. Front. Aging Neurosci. 6:289. doi: 10.3389/fnagi.2014.00289

Sandrini, M., Manenti, R., Brambilla, M., Cobelli, C., Cohen, L. G., and Cotelli, M. (2016). Older adults get episodic memory boosting from noninvasive stimulation of prefrontal cortex during learning. Neurobiol. Aging 39, 210-216. doi: 10.1016/j.neurobiolaging.2015.12.010

Sarter, M., Lustig, C., Howe, W. M., Gritton, H., and Berry, A. S. (2014). Deterministic functions of cortical acetylcholine. Eur. J. Neurosci. 39, 1912-1920. doi: 10.1111/ejn.12515

Sauseng, P., Griesmayr, B., Freunberger, R., and Klimesch, W. (2010). Control mechanisms in working memory: a possible function of EEG theta oscillations. Neurosci. Biobehav. Rev. 34, 1015-1022. doi: 10.1016/j.neubiorev.2009.12.006

Sawaguchi, T., and Goldman-Rakic, P. S. (1991). D1 dopamine-receptors in prefrontal cortex - involvement in working memory. Science 251, 947-950. doi: $10.1126 /$ science. 1825731

Scheff, S. W., Price, D. A., Schmitt, F. A., and Mufson, E. J. (2006). Hippocampal synaptic loss in early Alzheimer's disease and mild cognitive impairment. Neurobiol. Aging 27, 1372-1384. doi: 10.1016/j.neurobiolaging.2005. 09.012

Scheldrup, M., Greenwood, P. M., McKendrick, R., Strohl, J., Bikson, M., Alam, M., et al. (2014). Transcranial direct current stimulation facilitates cognitive multitask performance differentially depending on anode location and subtask. Front. Hum. Neurosci. 8:665. doi: 10.3389/fnhum.2014.00665

Schmiedek, F., Lövdén, M., and Lindenberger, U. (2010). Hundred days of cognitive training enhance broad cognitive abilities in adulthood: findings from the COGITO study. Front. Aging Neurosci. 2:27. doi: 10.3389/fnagi.2010.00027

Schneider-Garces, N. J., Gordon, B. A., Brumback-Peltz, C. R., Shin, E., Lee, Y., Sutton, B. P., et al. (2010). Span, crunch, and beyond: working memory capacity and the aging brain. J. Cogn. Neurosci. 22, 655-669. doi: 10.1162 /jocn.2009.21230

Schuck, N. W., Doeller, C. F., Polk, T. A., Lindenberger, U., and Li, S. C. (2015). Human aging alters the neural computation and representation of space. Neuroimage 117, 141-150. doi: 10.1016/j.neuroimage.2015.05.031

Sehm, B., Schäfer, A., Kipping, J., Margulies, D., Conde, V., Taubert, M., et al. (2012). Dynamic modulation of intrinsic functional connectivity by transcranial direct current stimulation. J. Neurophysiol. 108, 3253-3263. doi: $10.1152 /$ jn.00606.2012
Servan-Schreiber, D., Printz, H., and Cohen, J. D. (1990). A network model of catecholamine effects - gain, signal-to-noise ratio, and behavior. Science 249, 892-895. doi: $10.1126 /$ science. 2392679

Shing, Y. L., Werkle-Bergner, M., Brehmer, Y., Müller, V., Li, S.-C., and Lindenberger, U. (2010). Episodic memory across the lifespan: the contributions of associative and strategic components. Neurosci. Biobehav. Rev. 34, 1080-1091. doi: 10.1016/j.neubiorev.2009.11.002

Shing, Y. L., Werkle-Bergner, M., Li, S.-C., and Lindenberger, U. (2008). Associative and strategic components of episodic memory: a life-span dissociation. J. Exp. Psychol. 137, 495-513. doi: 10.1037/0096-3445.137.3.495

Simons, J. S., and Spiers, H. J. (2003). Prefrontal and medial temporal lobe interactions in long-term memory. Nat. Rev. Neurosci. 4, 637-648. doi: $10.1038 / \mathrm{nrn} 1178$

Singer, T., Lindenberger, U., and Baltes, P. B. (2003). Plasticity of memory for new learning in very old age: a story of major loss? Psychol. Aging 18, 306-317. doi: $10.1037 / 0882-7974.18 .2 .306$

Skolimowska, J., Wesierska, M., Lewandowska, M., Szymaszek, A., and Szelag, E. (2011). Divergent effects of age on performance in spatial associative learning and real idiothetic memory in humans. Behav. Brain Res. 218, 87-93. doi: $10.1016 / j . b b r .2010 .11 .03$

Smirni, D., Turriziani, P., Mangano, G. R., Cipolotti, L., and Oliveri, M. (2015). Modulating memory performance in healthy subjects with transcranial direct current stimulation over the right dorsolateral prefrontal cortex. PLOS ONE 10:e0144838. doi: 10.1371/journal.pone.0144838

Smith, T. D., Adams, M. M., Gallagher, M., Morrison, J. H., and Rapp, P. R. (2000). Circuit-specific alterations in hippocampal synaptophysin immunoreactivity predict spatial learning impairment in aged rats. J. Neurosci. 20, 6587-6593.

Soiza-Reilly, M., Fossati, M., Ibarra, G. R., and Azcurra, J. M. (2004). Different dopamine D1 and D2 receptors expression after motor activity in the striatal critical period. Brain Res. 1004, 217-221. doi: 10.1016/j.brainres.2004.01.050

Stagg, C. J., Best, J. G., Stephenson, M. C., O'Shea, J., Wylezinska, M., Kincses, Z. T., et al. (2009). Polarity-sensitive modulation of cortical neurotransmitters by transcranial stimulation. J. Neurosci. 29, 5202-5206. doi: 10.1523/JNEUROSCI.4432-08.2009

Stagg, C. J., and Nitsche, M. A. (2011). Physiological basis of transcranial direct current stimulation. Neuroscientist 17, 37-53. doi: 10.1177/1073858410386614

Stephens, J. A., and Berryhill, M. E. (2016). Older adults improve on everyday tasks after working memory training and neurostimulation. Brain Stimul. 9, 553-559. doi: 10.1016/j.brs.2016.04.001

Strafella, A. P., Paus, T., Barrett, J., and Dagher, A. (2001). Repetitive transcranial magnetic stimulation of the human prefrontal cortex induces dopamine release in the caudate nucleus. J. Neurosci. 21, 1-4.

Summers, J. J., Kang, N., and Cauraugh, J. H. (2016). Does transcranial direct current stimulation enhance cognitive and motor functions in the ageing brain? A systematic review and meta- analysis. Ageing Res. Rev. 25, 42-54. doi: 10.1016/j.arr.2015.11.004

Tanaka, T., Takano, Y., Tanaka, S., Hironaka, N., Kobayashi, K., Hanakawa, T., et al. (2013). Transcranial direct-current stimulation increases extracellular dopamine levels in the rat striatum. Front. Syst. Neurosci. 7:6. doi: $10.3389 /$ fnsys.2013.00006

Thompson, T. W., Waskom, M. L., and Gabrieli, J. D. (2016). Intensive working memory training produces functional changes in large-scale frontoparietal networks. J. Cogn. Neurosci. 28, 575-588. doi: 10.1162/jocn_a_00916

Thurm, F., Schuck, N. W., Fauser, M., Doeller, C. F., Stankevich, Y., Evens, R., et al. (2016). Dopamine modulation of spatial navigation memory in Parkinson's disease. Neurobiol. Aging 38, 93-103. doi: 10.1016/j.neurobiolaging.2015.10.019

Tseng, P., Hsu, T. Y., Chang, C. F., Tzeng, O. J., Hung, D. L., Muggleton, N. G., et al. (2012). Unleashing potential: transcranial direct current stimulation over the right posterior parietal cortex improves change detection in low-performing individuals. J. Neurosci. 32, 10554-10561. doi: 10.1523/JNEUROSCI.0362-12.2012

Wager, T. D., and Smith, E. E. (2003). Neuroimaging studies of working memory. Cogn. Affect. Behav. Neurosci. 3, 255-274. doi: 10.3758/CABN.3.4.255

Wenger, E., Schaefer, S., Noack, H., Kühn, S., Mårtensson, J., Heinze, H. J., et al. (2012). Cortical thickness changes following spatial navigation training in adulthood and aging. Neuroimage 59, 3389-3397. doi: 10.1016/j.neuroimage.2011.11.015 
Wiener, J. M., de Condappa, O., Harris, M. A., and Wolbers, T. (2013). Maladaptive bias for extrahippocampal navigation strategies in aging humans. J. Neurosci. 33, 6012-6017. doi: 10.1523/jneurosci.0717-12.2013

Williams, G. V., and Goldman-Rakic, P. S. (1995). Modulation of memory fields by dopamine d1 receptors in prefrontal cortex. Nature 376, 572-575. doi: $10.1038 / 376572 \mathrm{a} 0$

Willis, S. L., Tennstedt, S. L., Marsiske, M., Ball, K., Elias, J., Koepke, K. M., et al. (2006). Long-term effects of cognitive training on everyday functional outcomes in older adults. J. Am. Med. Assoc. 296, 2805-2814. doi: 10.1001/jama.296.23.2805

Wilson, I. A., Gallagher, M., Eichenbaum, H., and Tanila, H. (2006). Neurocognitive aging: prior memories hinder new hippocampal encoding. Trends Neurosci. 29, 662-670. doi: 10.1016/j.tins.2006.10.002

Wolbers, T., and Büchel, C. (2005). Dissociable retrosplenial and hippocampal contributions to successful formation of survey representations. J. Neurosci. 25, 3333-3340. doi: 10.1523/JNEUROSCI.4705-04.2005

Wolbers, T., Wiener, J. M., Mallot, H. A., and Büchel, C. (2007). Differential recruitment of the hippocampus, medial prefrontal cortex, and the human motion complex during path integration in humans. J. Neurosci. 27, 9408-9416. doi: 10.1523/jneurosci.2146-07.2007

Wong, D. F., Wagner, H. N. Jr., Dannals, R. F., Links, J. M., Frost, J. J., Ravert, H. T., et al. (1984). Effects of age on dopamine and serotonin receptors measured by positron tomography in the living human-brain. Science 226, 1393-1396. doi: $10.1126 /$ science. 6334363

Yamamoto, M., Suhara, T., Okubo, Y., Ichimiya, T., Sudo, Y., Inoue, M., et al. (2002). Age-related decline of serotonin transporters in living human brain of healthy males. Life Sci. 71, 751-757. doi: 10.1016/s0024-3205(02)01745-9

Zaehle, T., Sandmann, P., Thorne, J. D., Jäncke, L., and Herrmann, C. S. (2011). Transcranial direct current stimulation of the prefrontal cortex modulates working memory performance: combined behavioural and electrophysiological evidence. BMC Neurosci. 12:2. doi: 10.1186/1471-2202-12-2

Zahrt, J., Taylor, J. R., Mathew, R. G., and Arnsten, A. F. T. (1997). Supranormal stimulation of D-1 dopamine receptors in the rodent prefrontal cortex impairs spatial working memory performance. J. Neurosci. 17, 8528-8535.
Zatorre, R. J., Fields, R. D., and Johansen-Berg, H. (2012). Plasticity in gray and white: neuroimaging changes in brain structure during learning. Nat. Neurosci. 15, 528-536. doi: 10.1038/nn.3045

Zhang, Z., Cordeiro Matos, S., Jego, S., Adamantidis, A., and Séguéla, P. (2013). Norepinephrine drives persistent activity in prefrontal cortex via synergistic $\alpha 1$ and $\alpha 2$ Adrenoceptors. PLoS ONE 8:e66122. doi: 10.1371/journal.pone. 0066122

Zimerman, M., and Hummel, F. C. (2010). Non-invasive brain stimulation: enhancing motor and cognitive functions in healthy old subjects. Front. Aging Neurosci. 2:149. doi: 10.3389/fnagi.2010.00149

Zinke, K., Zeintl, M., Rose, N. S., Putzmann, J., Pydde, A., and Kliegel, M. (2014). Working memory training and transfer in older adults: effects of age, baseline performance, and training gains. Dev. Psychol. 50, 304-315. doi: $10.1037 / \mathrm{a} 0032982$

Zwissler, B., Sperber, C., Aigeldinger, S., Schindler, S., Kissler, J., and Plewnia, C. (2014). Shaping memory accuracy by left prefrontal transcranial direct current stimulation. J. Neurosci. 34, 4022-4026. doi: 10.1523/JNEUROSCI.5407-13.2014

Conflict of Interest Statement: The authors declare that the research was conducted in the absence of any commercial or financial relationships that could be construed as a potential conflict of interest.

The reviewer YS declared a shared secondary affiliation, though no other existing collaboration, with one of the authors SL to the handling Editor, who ensured that the process nevertheless met the standards of a fair and objective review.

Copyright (C) 2017 Passow, Thurm and Li. This is an open-access article distributed under the terms of the Creative Commons Attribution License (CC BY). The use, distribution or reproduction in other forums is permitted, provided the original author(s) or licensor are credited and that the original publication in this journal is cited, in accordance with accepted academic practice. No use, distribution or reproduction is permitted which does not comply with these terms. 